\title{
La secuencia musteriense de la Cueva del Niño (Aýna, Albacete) y el poblamiento neandertal en el sureste de la Península Ibérica
}

\author{
The Mousterian sequence from El Niño cave (Aýna, Albacete) and the Neanderthal \\ occupation of south-eastern Iberia
}

\author{
Alejandro García Moreno (*) (***) \\ Joseba Rios Garaizar (**) \\ Ana Belén Marín Arroyo (***)
}

\author{
José Eugenio Ortíz (****) \\ Trinidad de Torres (****) \\ Inés López-Dóriga $(* * *)$
}

\begin{abstract}
RESUMEN
En este artículo se presentan los resultados de la revisión de los materiales arqueológicos procedentes de la excavación realizada en 1973 en la Cueva del Niño (Aýna, Albacete) correspondientes a ocupaciones del Paleolítico Medio. Esta revisión se realizó fundamentalmente mediante el análisis tecnológico de la industria lítica, el estudio arqueozoológico y tafonómico de los restos de macromamíferos y el análisis de los restos carpológicos. Además, se presentan las dataciones obtenidas para los niveles revisados. Estas dataciones sitúan la ocupación de la cavidad a finales del MIS3. A pesar del reducido número de restos arqueológicos disponibles, la información resultante permite situar el yacimiento de la Cueva del Niño en el contexto del final del Paleolítico Medio del sureste de la Península Ibérica, y aportar nuevos datos a la problemática de la desaparición de las últimas poblaciones neandertales.
\end{abstract}

(*) MONREPOS Archaeological Research Centre and Museum for Human Evolution Behaviour. Römisch-Germanisches Zentralmuseum Mainz (RGZM). Monrepos Schloss. 56567 Neuwied. Alemania. Correo e.: garcia@rgzm.de

$(* *)$ Centro Nacional de Investigación en Evolución Humana. Paseo Sierra de Atapuerca s/n. 09002 Burgos.

Correo e.: joseba.rios@cenieh.es

$(* * *)$ Laboratorio de bioarqueología. Instituto Internacional de Investigaciones Prehistóricas de Cantabria. Universidad de Cantabria, Edif. Interfacultativo. Avda. Los Castros $\mathrm{s} / \mathrm{n}$. 39005 Santander.

Correos e.: anabelen.marin@unican.es; lopezli@unican.es

$(* * * *)$ Laboratorio de Estratigrafía Biomolecular. Escuela Técnica Superior de Ingenieros (ETSI) de Minas. Universidad Politécnica de Madrid. C/ Ríos Rosas 21. 28003 Madrid.

Correos e.: joseeugenio.ortiz@upm.es; trinidad.torres@upm.es Recibido: 16-III-2013; aceptado: 3-X-2013.

\begin{abstract}
This paper reviews the results obtained from the 1973 excavation of El Niño cave (Aýna, Albacete), corresponding to the Middle Palaeolithic occupations of the site. We present the technological analysis of lithic assemblages, the archaeozoological and taphonomical analysis of faunal remains, the analysis of plant macro remains, and the dates obtained for the archaeological levels. These dates place the Mousterian occupations of El Niño during MIS3. Despite the reduced number of archaeological remains, the results obtained permit the cave of El Niño cave to be placed within the context of Late Middle Palaeolithic in south-eastern Iberia, and provide new data regarding the process of extinction of the last Neanderthal populations.
\end{abstract}

Palabras clave: Paleolítico Medio; Sureste de la Península Ibérica; Tecnología lítica; Arqueozoología; Arqueobotánica; Subsistencia; Neandertales.

Key words: Middle Palaeolithic; South-eastern Iberia; Lithic technology; Archaeozoology; Archaeobotany; Subsistence; Neanderthals.

\section{INTRODUCCIÓN}

La Cueva del Niño (municipio de Aýna, Albacete) es conocida principalmente por ser uno de los pocos yacimientos en el interior de la Península Ibérica que conserva pinturas rupestres paleolíticas fuera de los principales núcleos cantábrico y levantino (Garate Maidagan y Gar- 
cía Moreno 2011). Las evidencias de ocupaciones epipaleolíticas y neolíticas han sido también tratadas con cierta profundidad (Martí Oliver 1988; Rodríguez González 2008; García Atiénzar 2011). Sin embargo la presencia de niveles paleolíticos se ha mantenido prácticamente inédita 40 años después de las excavaciones (Higgs et al. 1976; Davidson 1986), al no haberse publicado en su totalidad la tesis doctoral de Davidson (1).

Los niveles del Paleolítico Medio tienen especial interés por la importancia de la sucesión de ocupaciones y por la propia localización de la cueva. Los restos líticos, faunísticos y botánicos conservados nos aproximan al poblamiento neandertal en esta región de la Submeseta Sur en diferentes momentos del período y nos permiten evaluar su vinculación con otros ámbitos cercanos como la Bética o la zona levantina (Serna López 1999; Cortés Sánchez 2007a, 2011; Zilhão y Villaverde 2008). El yacimiento se sitúa en una zona crucial para estudiar la transición del Paleolítico Medio al Superior y la extinción de los neandertales, un tema sobre el que en los últimos años se ha mantenido un interesante debate por la probabilidad de pervivencia de grupos de neandertales hasta ca $30 \mathrm{ka}$ BP en áreas refugio del Sur de la Península Ibérica (Soffer 2000; Zilhão 2006; Finlayson et al. 2006; Finlayson et al. 2008; Walker et al. 2008 contra Wood et al. 2013).

El objetivo de este trabajo es revisar el material lítico, faunístico y botánico recuperado en los niveles musterienses excavados en 1973 y obtener un encuadre cronológico para las ocupaciones humanas de la cavidad. El que la industria lítica y la cronología sean asociables a Homo neandertalensis nos permitirá poner en valor este yacimiento e integrarlo en el debate científico sobre la evolución del Paleolítico Medio en el sureste peninsular. Ello hará posible apuntar algunas ideas, aunque necesariamente limitadas dado lo fragmentario del registro, acerca de los procesos de transformación de las sociedades neandertales y de su eventual desaparición.

(1) Davidson, I. Late Palaeolithic Economy in Eastern Spain. Tesis doctoral inédita. University of Cambridge. Cambridge, 1981 (véase capítulo 10).

\section{LOCALIZACIÓN, DESCRIPCIÓN DEL YACIMIENTO E HISTORIA DE LAS INTERVENCIONES}

La Cueva del Niño (UTM-ED50 30T $573597-$ 4266251) se encuentra en el municipio de Aýna, al Sur de la provincia de Albacete (Fig. 1), en la Sierra del Segura. Como eslabón más septentrional de la Cordillera Bética sirve de transición entre esta última cadena y la llanura manchega. El emplazamiento se enmarca en un tramo de la cuenca media del río Mundo, afluente del río Segura, que discurre entre cañones excavados en las calizas del Jurásico, conformando un paisaje abrupto caracterizado por un relieve de gran energía. Los cañones se abren sobre sedimentos del Liásico fuertemente plegados, resultando en un paisaje ondulado de penillanuras salteadas por colinas y masas calcáreas de cierta entidad, como los picos de la Peña de la Albarda (1.254 m) y el Pico del Halcón (1.230 m), bajo el que se encuentra la cueva. En esta región con grandes contrastes físicos, los espacios abiertos se alternan con entornos típicamente serranos cortados por barrancos y cañones, dando lugar a una importante diversidad paisajística y ecológica.

La cueva está situada al pie de la pared norte del Barranco del Infierno (Fig. 2). Se abre en el extremo sur de un abrigo rocoso de unos $10 \mathrm{~m}$ de longitud, orientado al Este, la visera tiene unos

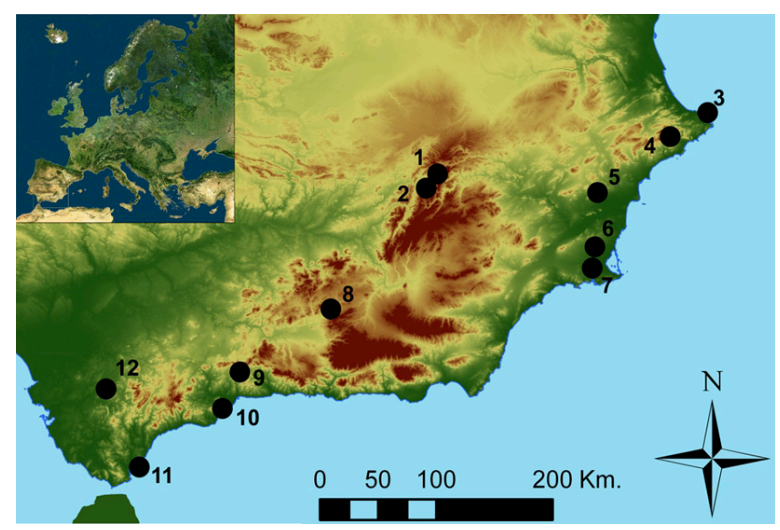

Fig. 1. Localización de la Cueva del Niño (1) en relación a otros conjuntos del Paleolítico Medio final del sureste de la Península Ibérica: El Palomar (2), Foradada (3), Beneito (4), Antón (5), Las Palomas (6), Aviones (7), Carihuela (8), Zafarraya (9), Bajondillo (10), Gorham's (11) e Higueral de Valleja (12). Mapa creado por A. García Moreno a partir del MDT200 distribuido por el CNIG. 


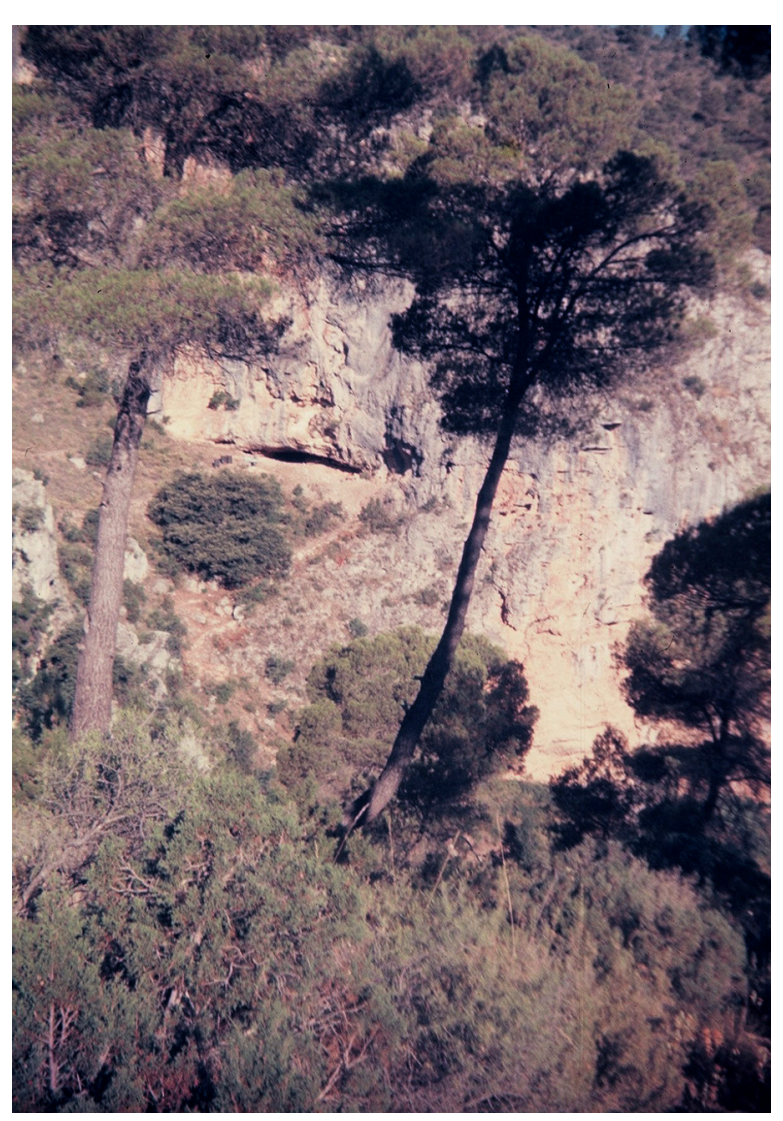

Fig. 2. Vista de la boca de la Cueva del Niño, donde puede apreciarse el abrupto paisaje donde se encuentra el yacimiento. Foto I. Davidson, 1973.

$3 \mathrm{~m}$ de longitud y la altura máxima es de unos $2 \mathrm{~m}$. A medida que nos alejamos de la boca, el abrigo va estrechándose y perdiendo ángulo con respecto a la alta pared vertical hasta que llega a confundirse con ella.

La cavidad presenta unos $30 \mathrm{~m}$ de desarrollo, de morfología ovalada. Una importante formación estalagmítica central permite distinguir dos salas. La primera es de forma semicircular, unos $15 \mathrm{~m}$ de diámetro y bastante amplia, ya que el techo va ganando altura desde la entrada. El suelo es regular, formado por un sedimento arcilloso muy suelto y polvoriento de color rojizo. En la pared izquierda, en una zona de penumbra, está el principal panel de pinturas paleolíticas (Garate Maidagan y García Moreno 2011). Una potente formación estalagmítica separa esta sala de la interior. Es de dimensiones similares pero con suelo mucho más irregular por la presencia de grandes bloques y un cono de derrubio que buza hacia el noreste con una fuerte inclinación. El segundo panel de pinturas (Garate Maidagan y García Moreno 2011) se encuentra en un pequeño divertículo lateral izquierdo de la sala.

El yacimiento se dio a conocer en 1970 con el descubrimiento y posterior publicación de su conjunto de pinturas rupestres paleolíticas y de estilo levantino (Almagro Gorbea 1971, 1972). En 1973 un equipo de la Universidad de Cambridge, dirigido por I. Davidson, sondeó la cavidad (Higgs et al. 1976; Davidson y García Moreno 2013) y prospectó la cuenca media del río Mundo, documentando yacimientos fundamentalmente del Paleolítico Medio y el Epipaleolítico (Davidson 1986; Serna López 1990).

Las excavaciones consistieron en dos trincheras y un sondeo en el abrigo exterior y una cata en el vestíbulo. La secuencia principal se definió en las Trench $1(2 \times 4 \mathrm{~m})$ y Trench $2(2 \times 3 \mathrm{~m})$, excavadas en paralelo al exterior frente a la entrada de la cavidad. Los excavadores llegaron hasta algo más de $3 \mathrm{~m}$ de profundidad, identificando un total de 11 unidades estratigráficas (Fig. 3), diferenciadas fundamentalmente por sus características sedimentológicas y contenido arqueológico. I. Davidson (2) las describió de techo a muro:

Nivel I: superficial, de tierra suelta y grisácea con manchas cenicientas y de arcilla rojiza.

Nivel II: en gran medida indistinguible del I salvo por algunos lentejones marrones. Contiene restos cerámicos.

Nivel III: tierra arcillosa compacta bajo los niveles grisáceos superiores. Hacia la parte inferior destacan los éboulis. Aparece intercalado en el IV.

Nivel IV: sedimento rojizo con abundantes plaquetas, formadas por fragmentos planos de caliza, probablemente procedentes del techo del abrigo.

Nivel V: sedimento arcilloso y muy compacto, de color rojizo, las plaquetas son sustituidas por rocas de mayor tamaño. En la base reaparecen algunas plaquetas.

Nivel VI: lentejones de sedimento rosáceo con plaquetas.

Nivel VII: sedimento arcilloso de color rojo oscuro con moteados de carbón.

(2) Véase n. 1. 
Nivel VIII: sedimento compacto de color rojizo con abundantes cantos redondeados completamente diferentes a los clastos de niveles superiores. Probablemente fueron depositados por agua. Hay manchas cenicientas intercaladas en el nivel.

Nivel IX: arenoso y rocoso de color anaranjado con algunas manchas grisáceas, que probablemente correspondan a depósitos de ocupación.

Nivel X: similar al VII, pero sin moteados de carbón. Una fina capa de sedimento rosáceo le separaba de los estratos superior e inferior.

Nivel XI base la secuencia: lentejones de color rojizo-grisáceo con una matriz de éboulis y algunas rocas de mayor tamaño.

En un primer momento, a partir de esta estratigrafía se identificaron tres períodos de ocupación de la cavidad (Higgs et al. 1976): la mitad inferior (Niveles XI a VII inclusive) correspondería al Paleolítico Medio y los dos primeros niveles al Epipaleolítico y/o Neolítico-Calcolítico ya de época holocena. Más problemática resultó la asignación crono-cultural de los Niveles III y IV, planteándose su posible correspondencia con un momento indeterminado del Paleolítico Superior. El análisis sedimentológico previsto durante la excavación (y para el que se tomaron las muestras correspondientes) no pudo ser completado (Davidson, com. pers.), a la vez que el relleno de las trincheras tras finalizar la intervención impide valorar in situ la secuencia. No obstante, la revisión de la industria lítica recuperada permite asignar al Paleolítico Medio toda la secuencia (Niveles III-IV al XI), salvo los niveles superiores. Ambos pertenecerían al Neolítico en función de los restos cerámicos (3) (Martí Oliver 1988), aunque les acompañaban restos líticos masivos de aspecto arcaico. Las (escasas) evidencias del uso de la cavidad durante el Paleolítico Superior quedarían restringidas a su interior (Garate Maidagan y García Moreno 2011).

La excavación en las diversas áreas del yacimiento (Higgs et al. 1976; Davidson y García Moreno 2013) proporcionó un total de 617 restos líticos (además de algunos recuperados en superficie sin adscripción estratigráfica), 121 cerámicos $(30$ procedentes de recogidas superficiales) y 1.963 fragmentos óseos de los que 318

(3) Chapman, Apéndice en Davidson 1981 (véase n. 1), pp. 50-55.

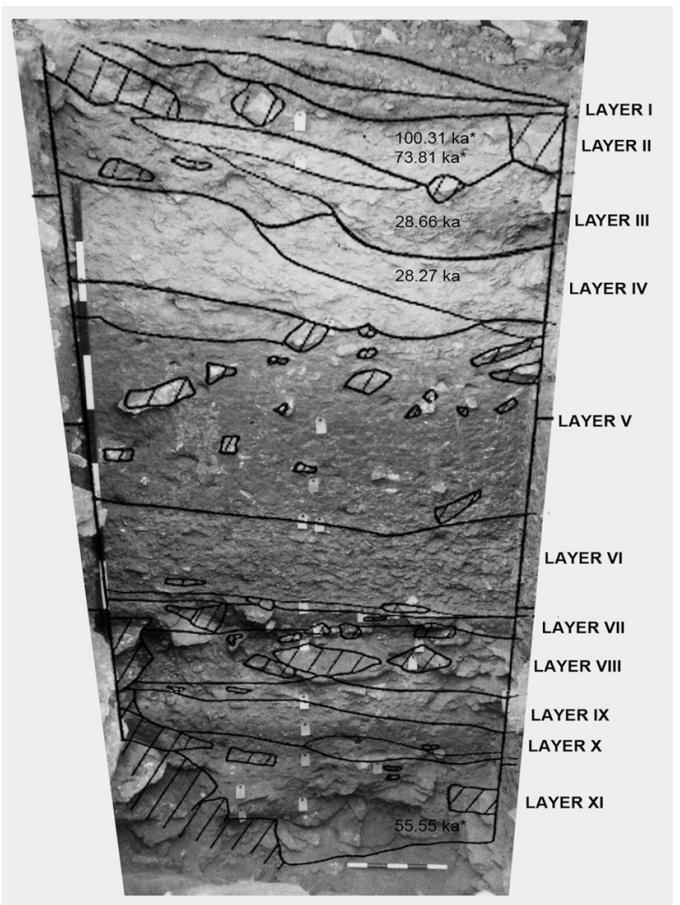

Fig. 3. Perfil estratigráfico de la Cueva del Niño (sección $\mathrm{O}$, Trench 2), con indicación de las dataciones disponibles (a partir de foto e interpretación estratigráfica de I. Davidson, inédito). Se han superpuesto las dataciones disponibles: * mediante AAR.

fueron identificados a nivel taxonómico y anatómico en el estudio preliminar (4). Aquí se presentan los resultados de la revisión y del análisis multidisciplinar de los hallazgos de los niveles asignados al Paleolítico Medio, es decir, procedentes de las dos trincheras mencionadas.

\section{INDUSTRIA LÍTICA}

El conjunto lítico musteriense (Niveles III-XI) comprende 137 restos. La mayoría se concentran en los Niveles IV y XI, la base de la secuencia. El conjunto ha sido analizado desde una perspectiva integral (Rios Garaizar 2007, 2012) que pretende una lectura económica de cada uno de los conjuntos y una visión diacrónica de la evolución del comportamiento de los grupos neandertales con respecto al aprovisionamiento tecnológico y a la función del yacimiento. No obstante el limitado número de restos (Tab. 1) y la reducida ex-

(4) Véase n. 1. 
tensión de la excavación impiden desarrollar por completo estos objetivos, aconsejando una interpretación cautelosa.

El Nivel III-IV proporcionó un total de 74 restos líticos: 61 de cuarcita y 13 de sílex. La cuarcita es una materia ultra-local, presente en conglomerados localizados a escasos metros de la cueva. Hemos identificado 4 variedades de cuarcita a partir del color, el grano y el córtex. El sílex se introduce en útiles ya conformados lo que, unido a su gran variabilidad material, induce a pensar que procediera de localidades distantes, como los afloramientos existentes en torno al Campo de Hellín, distantes unos 37 km (López Campuzano y Jordán Montés 1995; Jiménez Lorente et al. 1995-1996).

El conjunto está dominado por las lascas simples, desbordantes y en menor medida de decorticado. No se han recuperado núcleos y las evidencias de conformación y mantenimiento de utillaje son muy escasas, aunque esta imagen puede estar sesgada por la escasa muestra disponible.

Se han identificado tres series de remontajes en cuarcita incluyendo 11 restos $(14,8 \%$ del total recuperado). Estas series, unidas a la escasa variabilidad de tipos de cuarcita identificados, sugieren que solo unos pocos cantos fueron importados y tallados in situ. Dos de las series de remontados se han realizado sobre la misma variedad de cuarcita (Fig. 4). La talla se orienta a la obtención de lascas corticales de sección asimétrica y de gran tamaño, encuadrables en los sistemas tipo Quina (Bourguignon 1996). La ausencia de algunos elementos en la secuencia podría indicar que parte de las lascas se usaron en otros puntos del abrigo o fuera de él. Otros restos de esta misma variedad de cuarcita presentan características tecnológicas semejantes. Componen la tercera secuencia de remontado dos lascas de cuarcita de una variedad más fina. Refleja un episodio de producción de lascas desbordantes, tipo punta Pseudolevallois, mediante un esquema de producción Discoide cordal. Estas lascas tienen planta triangular, talones diedros asimétricos, ángulos de talla superiores a $110^{\circ}$ y negativos directos y oblicuos.

El análisis tecnológico del resto de la muestra en cuarcita ha permitido distinguir dos tipos de producción: Quina y Discoide. El sistema de tipo Quina da lugar a lascas corticales de sección asimétrica con negativos previos unipolares $\mathrm{u}$

\begin{tabular}{|c|c|c|c|c|c|}
\hline & \multicolumn{5}{|c|}{ Niveles } \\
\hline & III-IV & VII & VIII & $\mathbf{X}$ & $\mathbf{X I}$ \\
\hline $\begin{array}{l}\text { Núcleo de lascas sobre } \\
\text { lasca }\end{array}$ & & & & 1 & 1 \\
\hline Cuarcita & & & & 1 & \\
\hline Silex & & & & & 1 \\
\hline Lasca decorticado $1 .^{\circ}$ & & & 1 & 1 & 1 \\
\hline Cuarcita & & & 1 & 1 & 1 \\
\hline Lasca decorticado $2 .^{\circ}$ & 9 & 1 & 1 & 1 & 2 \\
\hline Cuarcita & 9 & 1 & 1 & 1 & \\
\hline Silex & & & & & 2 \\
\hline Lamina decort $1 .^{\circ}$ & 1 & & & & \\
\hline Silex & 1 & & & & \\
\hline Lasca desbordante & 18 & 1 & & 4 & 3 \\
\hline Cuarcita & 17 & 1 & & 2 & 2 \\
\hline Sillex & 1 & & & 2 & 1 \\
\hline Lasca sobrepasada & 4 & & & & 1 \\
\hline Cuarcita & 4 & & & & \\
\hline Silex & & & & & 1 \\
\hline Entame & 1 & & & & \\
\hline Cuarcita & 1 & & & & \\
\hline Lámina sobrepasada & 1 & & & & \\
\hline Silex & 1 & & & & \\
\hline Lasca & 16 & 3 & & 2 & 7 \\
\hline Marga & & & & & 2 \\
\hline Cuarcita & 12 & 2 & & 2 & 2 \\
\hline Silex & 4 & 1 & & & 3 \\
\hline Microlasca & 2 & & & & 3 \\
\hline Cuarcita & 2 & & & & \\
\hline Silex & & & & & 3 \\
\hline Lámina & 1 & & & & 1 \\
\hline Silex & 1 & & & & 1 \\
\hline Laminilla & 1 & & & & \\
\hline Cuarcita & 1 & & & & \\
\hline Lasca de reavivado & 1 & 4 & & 2 & 9 \\
\hline Cuarcita & & 2 & & & 4 \\
\hline Radiolarita & & & & & 1 \\
\hline Silex & 1 & 2 & & 2 & 4 \\
\hline Astilla & 3 & & & & \\
\hline Cuarcita & 2 & & & & \\
\hline Silex & 1 & & & & \\
\hline Informe & 15 & & 1 & & 12 \\
\hline Caliza & & & & & 1 \\
\hline Marga & & & & & 5 \\
\hline Cuarcita & 12 & & & & 5 \\
\hline Silex & 3 & & 1 & & 1 \\
\hline $\begin{array}{l}\text { Matriz testada o per- } \\
\text { cutor }\end{array}$ & & & & & \\
\hline Bloque & 1 & & & & \\
\hline Cuarcita & 1 & & & & \\
\hline Total general & 74 & 9 & 3 & 11 & 40 \\
\hline Silex & 13 & 3 & 1 & 4 & 17 \\
\hline Cuarcita & 61 & 6 & 2 & 7 & 14 \\
\hline Marga & & & & & 7 \\
\hline Otros & & & & & 2 \\
\hline
\end{tabular}

Tab. 1. Clasificación tecnológica de los niveles musterienses de la Cueva del Niño (Aýna, Albacete). 

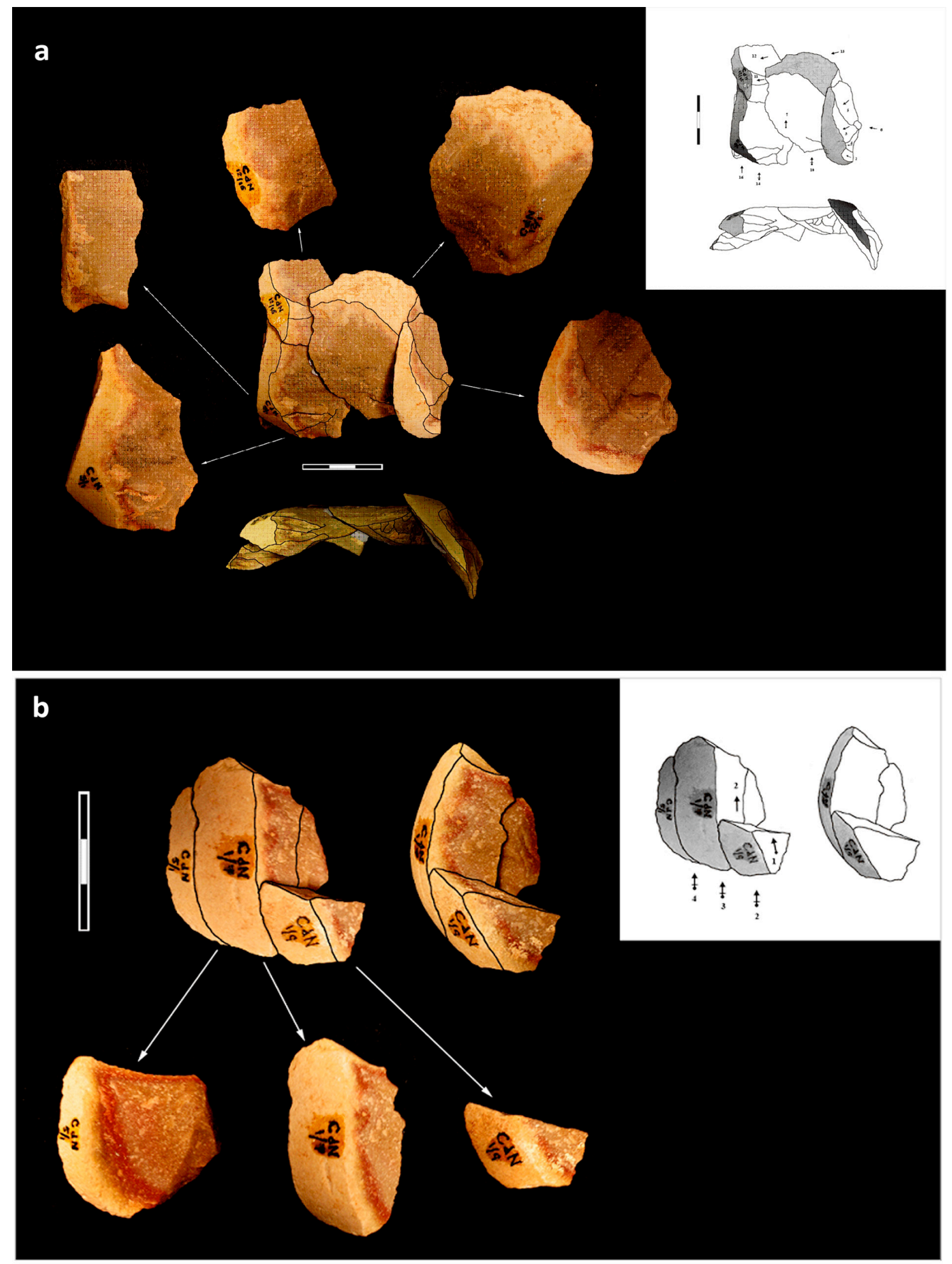

Fig. 4. Dos series de remontados sobre la misma variedad de cuarcita del Nivel III-IV de la Cueva del Niño (Ayna, Albacete): a) remontado de cinco lascas de cuarcita procedentes de una secuencia de talla tipo Quina, b) remontado de tres lascas. Foto J. Rios Garaizar. 
oblicuos y con talones lisos o diedros asimétricos. Son lascas con módulo cuadrangular y cierta tendencia al alargamiento. La cadena operativa de la producción de tipo Discoide está algo más fragmentada. Los restos corticales son escasos. Las lascas tienen negativos centrípetos, ángulos de talla inclinados y talones facetados y diedros asimétricos. La alta frecuencia de soportes desbordantes sugiere un esquema de tipo cordal. Resulta más complicado definir el sistema de producción en el sílex por el alto grado de fragmentación de la cadena operativa de la muestra. Sin embargo la morfología de los restos, los negativos unipolares y centrípetos y la alta frecuencia de talones preparados (facetados y diedros) sugieren un método de fabricación de tipo Levallois.

En el Nivel III-IV, el utillaje retocado es muy escaso $(\mathrm{N}=4)$ (Fig. 5). En sílex hay una punta musteriense alargada (Tip Cross Section Area: $62,5 \mathrm{~mm}^{2}$ ), una raedera simple convexa y una raedera doble recto-cóncava y en cuarcita una lasca truncada. Tan solo se ha documentado una lasca de reavivado (tipo 2 sensu Bourguignon 1996), realizada en sílex evaporítico, lo que sugiere actividades poco intensas de conformación de utillaje o de mantenimiento. El utillaje bruto es más abundante destacando las lascas asimétricas tipo gajo de naranja o las puntas Pseudolevallois de cuarcita.

Según estas características tecnológicas y tipológicas existen 3 modalidades principales de fabricación: a) una de tipo Quina que se realiza in situ sobre cuarcita; b) una a partir de núcleos centrípetos de tipo Discoide cordal o Levallois ejecutada en cuarcita, probablemente fuera del sitio y c) una Levallois en sílex gestionada fuera $\mathrm{y}$, posiblemente, a cierta distancia del yacimiento, para producir útiles que se desplazan por el territorio.

En el entorno del yacimiento son corrientes los hallazgos superficiales de núcleos y soportes de tipo Levallois y Discoide en cuarcita asignables a la segunda modalidad de producción (Serna López 1990, 1999).

Los datos de la muestra, aunque contados, parecen indicar una ocupación efímera en el Nivel III-IV. La baja densidad de restos y de intensidad en las actividades de fabricación, acondicionamiento $\mathrm{y}$, aparentemente, uso del utillaje lítico apuntan en este sentido. Su gestión indica también que son grupos que se desplazan por el territorio con parte del utillaje necesario. El resto
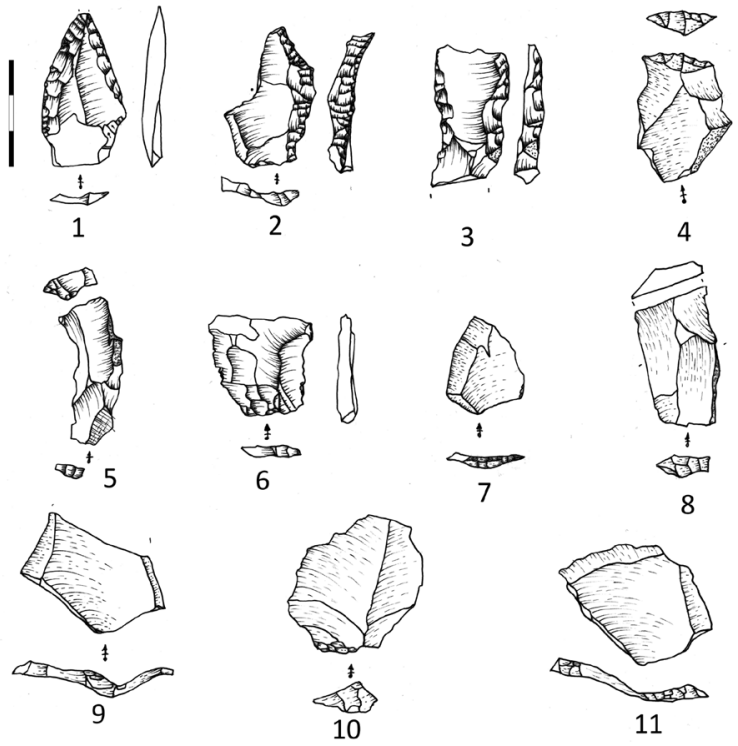

7

8
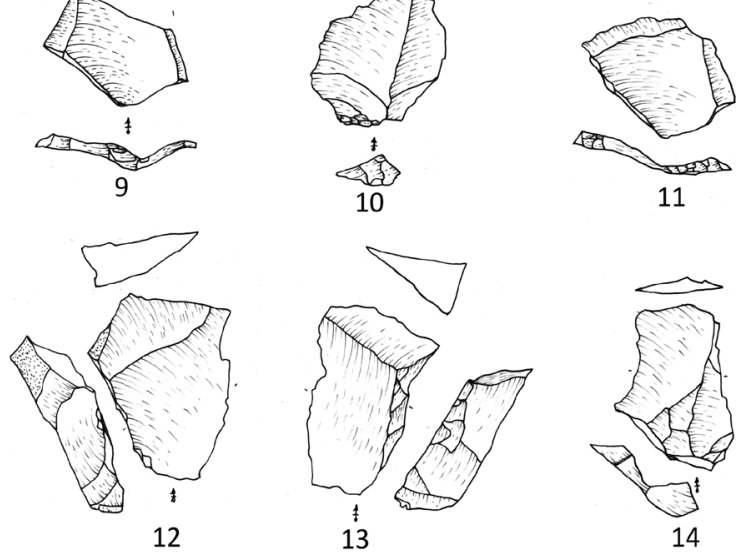

Fig. 5. Utillaje del nivel III-IV de la Cueva del Niño: 1 punta Musteriense; 2-3 raederas; 4 lasca truncada; 5-11 lascas Levallois; 12-14 puntas Pseudolevallois. Materia prima 1 indeterminada, 2, 3, 5, 6 sílex, 4, 7-14 cuarcita. Dibujo J. Rios Garaizar.

del utillaje se realiza in situ o en puntos cercanos a partir de las materias primas locales $\mathrm{y}$, parece, sin incorporarse de manera significativa a los circuitos de desplazamiento de los grupos neandertales una vez se abandona la Cueva del Niño.

Se trata de un pequeño conjunto cuyas características tecno-tipológicas son consistentes con una atribución al Paleolítico Medio y, en parte, se comparten con los conjuntos del final del Paleolítico Medio de las regiones vecinas: aumento del uso de materias primas locales, presencia de talla Levallois y Discoide o escasa importancia de las raederas (Vega Toscano et al. 1988; Fernández Peris et al. 1997; Galván Santos et al. 2001; Villaverde Bonilla 2001; Cortés Sánchez 2007b; Walker et al. 2008; Zilhão y Villaverde 2008; Lorenzo et al. 2012; Pacheco et al. 2012). 


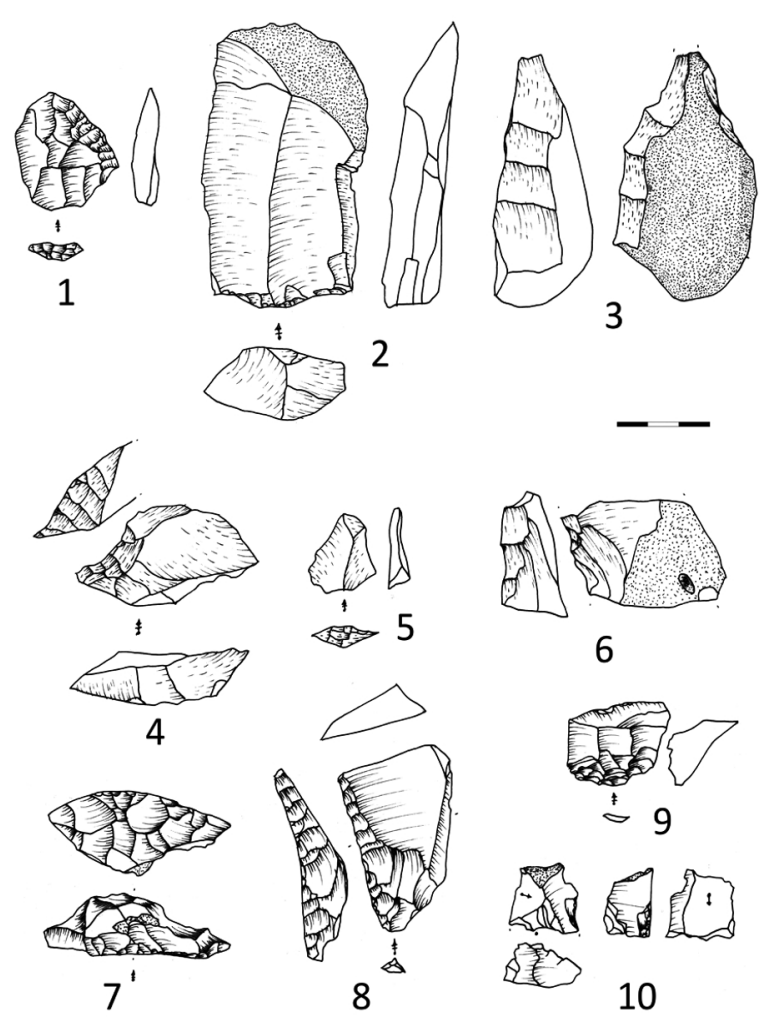

Fig. 6. Utillaje lítico de los niveles inferiores de la Cueva del Niño. Nivel VII: 1 raedera recta; 2 lasca de decorticado secundario. Nivel VIII: 3 pico Pseudoasturiense. Nivel X: 4 raedera cóncava; 5 punta Levallois; 6 denticulado. Nivel XI: 7 limace; 8 raedera recta; 9 lasca de reavivado con retoque discontinuo; 10 núcleo de microlascas. Materias primas: 1, 7-10 sílex, 2-6 cuarcita. Dibujo J. Rios Garaizar.

Los Niveles VII y VIII parecen resultado de ocupaciones efímeras de la cueva, dados los 12 efectivos recuperados. Del Nivel VII proceden 9 lascas: 1 de decorticado secundario (Fig. 6: 1) y 1 desbordante, ambas de cuarcita; 3 simples, dos de cuarcita y una de sílex; 4 de reavivado dos de cuarcita (tipos IV y V sensu Bourguignon 1996) y dos de sílex (tipos II y V). Entre los soportes hay ejemplos claros de talla Levallois con talones facetados y negativos directos o centrípetos. Los retocados son 2 raederas (Fig. 6: 2) y 1 denticulado. Del Nivel VIII, en cuarcita, hay 1 raedera Clactoniense y 1 pico (Fig. 6: 3) y, en sílex, 1 fragmento de útil.

El Nivel X está separado del VIII por una capa estéril y del XI por otra de sedimento grosero de color rosado. Se han recuperado 12 restos (Fig. 6): 1 núcleo Discoide de cuarcita y el resto lascas.
Hay 2 corticales de cuarcita; 4 desbordantes, dos de cuarcita y dos de sílex, 2 simples de cuarcita y 3 de reavivado Clactonienses de sílex (2 tipo IV y 1 tipo V). Hay evidencias de talla Discoide y Levallois y otros elementos que aluden a fases de desbastado inicial de núcleos de cuarcita. Los soportes de sílex están muy explotados, son de tamaño reducido y evidencian tecnologías con un uso prolongado en el tiempo.

El Nivel XI es el más rico de los estratos inferiores: 40 restos. Este nivel es el único donde el sílex es la materia prima más representada y donde hay más variedad de rocas. Entre ellas hay 7 restos de una roca sedimentaria de grano fino tipo marga, blanda de color blanquecino además de un resto de radiolarita y otro de caliza.

Se ha recuperado un núcleo de sílex para micro lascas $(21 \times 21 \times 13 \mathrm{~mm}, 6$ g, Fig. 6: 10). Se corresponde con una estrategia ramificada, que permite la explotación intensiva de un pequeño soporte de sílex que se utiliza como útil y, posteriormente, antes de su abandono como matriz para una nueva generación de lascas. Además hay 18 soportes primarios y 8 lascas de reavivado, cuatro de cuarcita, tres de sílex y una de radiolarita que provienen del reavivado o la producción de raederas Quina.

Los soportes de cuarcita presentan características propias de talla Discoide, con talones diedros asimétricos y corticales. Son lascas de tamaño considerable $(>30 \mathrm{~mm})$ que muestran negativos centrípetos en la cara dorsal. La roca sedimentaria de grano fino ha sido fabricada mediante un sistema de tipo centrípeto con talones lisos.

En sílex hay 3 lascas atribuibles a sistemas de producción Levallois. Son de tamaño medio. Presentan negativos unipolares y centrípetos y talones preparados (diedros asimétricos y facetados). Otras dos lascas son asimilables a una producción de tipo Quina, espesas, con talones amplios y superficies corticales que han sido intensamente retocadas. Por último hay una serie de pequeñas lascas que posiblemente provienen de una estrategia ramificada.

Hay 5 útiles retocados (Fig. 6): 3 raederas de sílex, todas ellas con evidencias de intensos reavivados y 2 lascas, una con retoque hacia la cara plana de cuarcita y otra de reavivado de sílex con retoques discontinuos.

El Nivel XI destaca en el conjunto de los niveles inferiores de la Cueva del Niño por las grandes lascas de tecnología Quina, de sílex y de 
cuarcita. Se introducen en el yacimiento como útiles retocados, son objeto de un intenso mantenimiento y sirven como matrices para una producción ramificada de tipo Quina. Esta producción se complementa con un uso más anecdótico de materias estrictamente locales como margas o cuarcitas de peor calidad. El nivel muestra características propias de una ocupación intensa y corta, realizada por unas poblaciones de gran movilidad. Este tipo de estrategias ha sido documentada en yacimientos franceses y de la Península Ibérica (Bourguignon et al. 2004; Soressi 2004; Rios Garaizar 2005, 2008, 2010; Costamagno et al. 2006; Carrión Santafé et al. 2008; Fernández Peris et al. 2008; Navazo y Díez 2008; Villaverde Bonilla et al. 2008).

El reducido tamaño de la muestra manejada de la Cueva del Niño no ha impedido determinar la variabilidad tecnológica a lo largo de la secuencia musteriense. El análisis de los Niveles musterienses (III-IV, VII, VIII, X y XI) ha puesto de relieve algunos elementos comunes, pero fundamentalmente permite plantear la existencia de cierta variabilidad en los tipos de ocupación, actividades realizadas, uso de materias primas y estrategias de aprovisionamiento y mantenimiento del utillaje (Tab. 2).

En los cinco niveles la escasez de restos posiblemente refleja ocupaciones poco intensas que cuestionarían el papel de la Cueva del Niño como centro referencial (Galván Santos et al. 2001) durante el Paleolítico Medio. Se observan algunas diferencias en el uso de materias primas entre la base de la secuencia donde la cuarcita, materia prima local, pierde importancia; los niveles intermedios donde domina claramente y el Nivel IIIIV con un aporte más intenso de materia prima local, objeto de una explotación in situ, y al que el sílex llega bajo formatos muy concretos.

En todos los niveles se documentan estrategias relacionadas con la movilidad pero algunas varían. En el Nivel XI están destinadas a favorecer el aporte de materias primas de calidad, mientras en el III-IV se aportan algunos útiles ya conformados y se fabrican los útiles necesarios, aprovechando las materias primas locales. Estas diferencias se traducen también en una gestión ramificada de la producción en el Nivel XI, muy relacionada con los sistemas de tipo Quina, y unas estrategias de fabricación fundamentalmente Discoide y Levallois en los niveles superiores.

\section{ANÁLISIS ARQUEOZOOLÓGICO}

El análisis arqueozoológico completa el trabajo inicial de Iain Davidson realizado tras la excavación de la Cueva del Niño en 1973. Davidson se centró sobre todo en la identificación anatómica y taxonómica de los restos óseos recuperados.

\begin{tabular}{|l|c|c|c|}
\hline & $\begin{array}{c}\text { Cueva del Niño Nivel } \\
\text { III-IV }\end{array}$ & $\begin{array}{c}\text { Cueva del Niño Nivel } \\
\text { XI }\end{array}$ & $\begin{array}{c}\text { Yacimientos al aire } \\
\text { libre }\end{array}$ \\
\hline Materias primas locales (cuarcita) & ++ & + & ++ \\
\hline Sílex $15-30 \mathrm{~km}$ & - & - & + \\
\hline Sílex $>30 \mathrm{~km}$ & + & ++ & +++ \\
\hline Producción primaria in situ & ++ & ++ & $-/+$ \\
\hline Ramificación & - & ++ & $-/+$ \\
\hline Mantenimiento utillaje & - & + & + \\
\hline $\begin{array}{l}\text { Especificidad funcional } \\
\text { materiales locales }\end{array}$ & + & + & + \\
\hline Levallois & ++ & ++ & ¿ \\
\hline Quina & ++ & ++ & +++ \\
\hline Discoide & ++ & - & - \\
\hline Puntas Musterienses & + & - & + \\
\hline Macroutillaje & - & + & + \\
\hline
\end{tabular}

Tab. 2. Aproximación cualitativa a la variabilidad de los Niveles III-IV y XI de la Cueva del Niño y los yacimientos al aire libre de la cuenca del río Mundo siguiendo el esquema definido por Rios Garaizar 2008. 
El estudio actual revisa ese mismo material e incorpora un análisis tafonómico detallado para conocer secuencialmente las actividades antrópicas realizadas, así como las alteraciones postdepósito acontecidas en el yacimiento. La revisión y estudio del material faunístico se hizo en el Grahame Clark Laboratory de la Universidad de Cambridge, donde estaba depositado.

Se ha aplicado la metodología utilizada por Marín Arroyo (2010). Los restos se identificaron con ayuda de las colecciones de referencia del Grahame Clark Laboratory y del Natural History Museum de Londres. Los que no pudieron identificarse taxonómica, pero sí anatómicamente se agruparon por su talla en la categoría de 'mamíferos grandes' (equino y bovino), 'medios' (ciervo y cabra) y 'pequeños' (corzo). Se creó la categoría de 'Megafauna' para restos de la talla del rinoceronte. Para la cuantificación del conjunto se calcularon los índices: Número de Restos (NR), Número Mínimo de Individuos (NMI) y Número Mínimo de Elementos (NME). Este último, por la escasez y fracturación de la muestra, no aportó información relevante para entender el tipo de transporte de los taxones representados. Para cuantificar el grado de homogeneidad y diversidad de la muestra taxonómica, relacionada con la amplitud de la dieta y el grado de aprovechamiento antrópico del medio, se obtuvo el Inverso del Índice de Simpson cuyo valor aumenta con el número de especies consumidas y con la uniformidad en sus capturas (Marín Arroyo y González Morales 2009: 54). Las características de la muestra impidieron estimar la estacionalidad de la ocupación.

Para reconocer la actividad antrópica en la cueva el análisis tafonómico se centró en las marcas de carnicería, el patrón de fracturación y las huellas de termoalteraciones. Entre las modificaciones bioestratinómicas cabe señalar la actividad de carnívoros, mientras que entre las diagenéticas, la principal alteración ha sido la disolución producida por períodos de encharcamiento dentro de la cueva.

La reducida muestra ósea aconseja cautela en la interpretación del conjunto. El Nivel XI contiene la mayor diversidad y cantidad de restos de fauna $(81 \%)$. Debido al mal estado de conservación de la muestra, solo ha sido posible identificar taxonómicamente un $8 \%$ de la misma, mientras que en un $63 \%$ se ha identificado únicamente la talla del mamífero y un $30 \%$ pertenece a esquirlas indeterminables de menos de $2 \mathrm{~cm}$. El número de identificaciones taxonómicas en los demás niveles, realmente escaso, dificulta la valoración del conjunto. El que los huesos identificados en los Niveles III-IV y X-XI como 'mamífero medio' sean probablemente de cérvidos y cápridos permite una aproximación parcial a las estrategias de subsistencia de los grupos neandertales. El Oryctolagus cuniculus aparece representado por elementos de todo el esqueleto, mayoritariamente en los Niveles X y XI, pero su importancia paleoeconómica es inapreciable. Los carnívoros identificados se restringen a cánido en el Nivel III y lince y úrsido en el XI.

Los 5 restos con identificación taxonómica de los Niveles III-IV son una falange próximal de Canis sp., un húmero y un fémur de Capra sp., un metápodo lateral de Cervus elaphus y un metatarso de Oryctolagus cuniculus. Los demás huesos identificados anatómicamente $(90 \%)$ eran fragmentos dentales y esquirlas (entre 1 y $5 \mathrm{~cm}$ ) atribuibles a mamíferos de talla media por el tamaño de la cortical y su morfología.

Los niveles inferiores, sobre todo el XI, cuentan con un mayor número de restos y de diversidad de especies (Tab. 3). En el X y el XI cápridos y cérvidos son los ungulados más frecuentes, si bien un $61 \%$ corresponden a mamíferos de talla media y un $26 \%$ a esquirlas indeterminables de menos de $2 \mathrm{~cm}$. El limitado total de huesos no excluye una representación proporcionalmente importante de mamíferos de gran talla, sobre todo Equus sp. en el Nivel XI y Bos primigenius en el $X$. Llama la atención el hallazgo de restos dentales de Dicerorhinus sp. en estos niveles inferiores, ya apuntado por Davidson (5), así como la relativa importancia de carnívoros en el Nivel XI, fundamentalmente Ursus sp. (varios metatarsos, falanges y un calcáneo) y Lynx sp. (epífisis proximal de un radio).

Las alteraciones bioestratinómicas de los restos faunísticos correspondientes a los niveles musterienses no incluyen marcas de corte, aunque sí evidencias de percusión directa y patrones de fracturación en fresco en un 3\% de los huesos de 'mamífero medio' en los Niveles IV, X y XI. Por último, en el Nivel XI un $8 \%$ de los huesos presentaban huellas de termoalteración pero solo uno aparecía quemado en el Nivel IV. La acción

(5) Véase n. 1.

Trab. prehist., 71, N. ${ }^{\circ}$ 2, julio-diciembre 2014, pp. 221-241, ISSN: 0082-5638

doi: $10.3989 /$ tp.2014.12132 


\begin{tabular}{|l|c|c|c|c|c|c|c|c|c|c|}
\hline \multirow{2}{*}{ Especie } & \multicolumn{2}{c|}{ Nivel III } & \multicolumn{2}{c|}{ Nivel IV } & \multicolumn{2}{c|}{ Nivel VIII } & \multicolumn{2}{c|}{ Nivel X } & \multicolumn{2}{c|}{ Nivel XI } \\
\cline { 2 - 12 } & NR & NMI & NR & NMI & NR & NMI & NR & NMI & NR & NMI \\
\hline Dicerorhinus sp. & & & & & & & 1 & 1 & 1 & 1 \\
\hline Bos primigenius & & & & & & & 1 & 1 & & \\
\hline Equus sp. & & & & & & & & & 13 & 4 \\
\hline Cervus elaphus & & & 1 & 1 & & & 5 & 1 & 4 & 1 \\
\hline Capreolus capreolus & & & & & & & & & 2 & 2 \\
\hline Capra sp. & 4 & 1 & 1 & 1 & 3 & 1 & 3 & 1 & 12 & 3 \\
\hline Ursus sp. & & & & & & & & & 9 & 2 \\
\hline Canis sp. & 1 & 1 & & & & & & & & \\
\hline Lynx sp. & & & & & & & & & 1 & 1 \\
\hline Oryctolagus cuniculus & & & 1 & 1 & & & 3 & 1 & 9 & 3 \\
\hline Megafauna & 17 & & 25 & & 1 & & 85 & & 389 & \\
\hline Mamífero medio & & & & & & & & & 18 & \\
\hline Mamífero grande & & & 2 & & & & & & 11 & \\
\hline Mamífero pequeño & & & & & & & & & 200 & \\
\hline Indeterminado & $\mathbf{2 2}$ & $\mathbf{2}$ & $\mathbf{3 0}$ & $\mathbf{3}$ & $\mathbf{4}$ & $\mathbf{1}$ & $\mathbf{9 8}$ & $\mathbf{5}$ & $\mathbf{6 7 1}$ & $\mathbf{1 7}$ \\
\hline TOTAL & & & & & & & & & 2 & \\
\hline
\end{tabular}

Tab. 3. NR y NMI totales por niveles y especies de la Cueva del Niño (Aýna, Albacete).

de carnívoros se ha identificado en un $0,7 \%$ de los huesos de la Trench 2: cinco habían sido digeridos (Niveles III y XI) y uno tenía marcas (Nivel XI).

Las alteraciones diagenéticas han producido un gran deterioro en los huesos. La disolución ha deteriorado un $80 \%$ de su superficie externa e interna (Fig. 7) por los continuados períodos de encharcamiento en la cueva, antes y después de la depositación. Estas alteraciones han impedido observar posibles alteraciones de carácter antrópico, como marcas de carnicería. En definitiva, el grado de fracturación de la muestra es tan elevado que ha limitado cuantitativamente su identificación taxonómica y anatómica. La figura 7 muestras como la longitud media de la mayoría de los fragmentos óseos de huesos largos $(\mathrm{N}=583)$ de los Niveles III, IV, X y XI no supera los $2 \mathrm{~cm}$.

El escaso número de restos recuperados y sus problemas de conservación han dificultado en gran medida la correcta valoración del espectro faunístico del Paleolítico Medio de la Cueva del Niño. No obstante puede realizarse una aproximación al mismo. El único taxón presente en toda la secuencia musteriense es Capra sp. Presupo- nemos que pertenecen a esta especie, junto a cérvidos, gran parte de los restos de ungulados de talla media que suponen el $63 \%$ del total de la muestra en Trench 2. Este dominio de la cabra no es de extrañar, ya que el yacimiento se sitúa en un entorno de roquedo, donde este animal es muy común aún hoy en día. La preponderancia de la cabra en el espectro cinegético indicaría un aprovechamiento preferente de los recursos locales por parte de los ocupantes de la cavidad.

Puede plantearse una cierta divergencia en la evolución diacrónica del conjunto entre los niveles inferiores de la secuencia (X y XI) y los superiores (III-IV). Faltan los restos pertenecientes a mamíferos de gran talla en los niveles más recientes que, en cambio, sí están en los más antiguos. Ello podría estar indicando una explotación estrictamente local de los recursos en la fase final del Paleolítico Medio. En los Niveles X y XI el caballo, predominante, aparece junto al uro y el rinoceronte. Ello podría estar indicando unas estrategias de subsistencia menos locales, aunque siempre supeditadas al dominio abrumador de los ungulados de talla media, principalmente cabras y algún ciervo. El Inverso del Índice de Simpson 


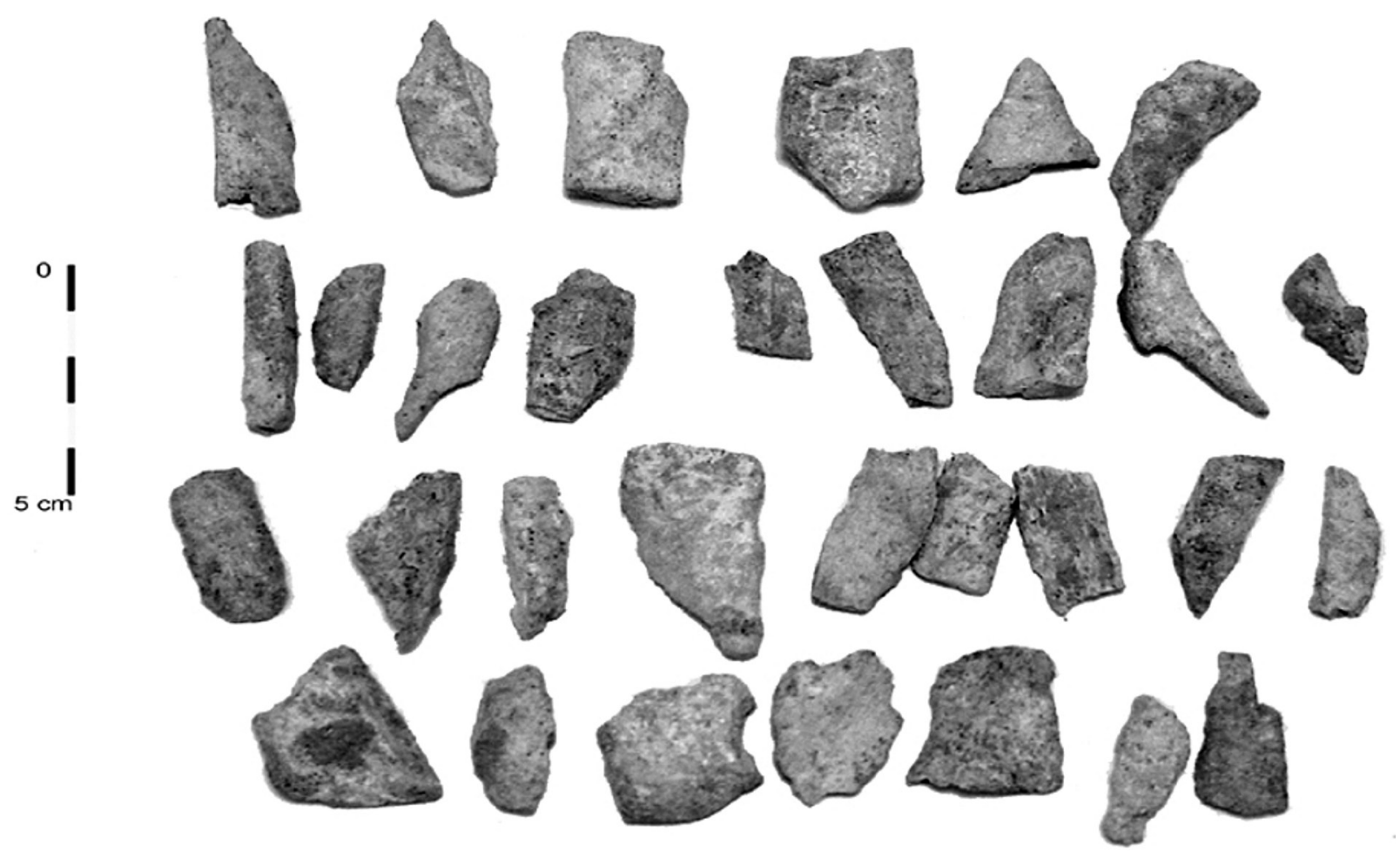

Fig. 7. Restos óseos procedentes del Nivel XI de la Cueva del Niño, donde puede apreciarse el alto grado de fragmentación y mal estado de conservación de la muestra. Foto A.B. Marín Arroyo.

a partir del NR de los ungulados identificados desde el Nivel III hasta el XI en la Trench 2 muestra un valor de 2 en los niveles inferiores y de 1,47 en los superiores. Este índice parece corroborar la hipótesis de una estrategia de subsistencia más diversificada en los niveles más antiguos, sucedida por una mayor restricción de la dieta con el consumo de especies próximas al yacimiento en momentos más recientes del Musteriense. La presencia del conejo en los Niveles $\mathrm{X}$ y XI no ha podido relacionarse con el consumo humano ni con su introducción por otros depredadores, dada la ausencia de huellas de manipulación antrópica y alteraciones de carnívoros.

\section{RESTOS CARPOLÓGICOS}

Los estudios de carporrestos en contextos pleistocenos son muy escasos. En la Península Ibérica solo se han publicado los de las cuevas de Gorham's y Vanguard en Gibraltar (Gale y Ca- rruthers 2000), la cueva de Nerja en Málaga (Badal García 1998), la cueva de El Juyo en Cantabria (Crowe 1985) y la cueva de Santa María en Alicante (Aura Tortosa et al. 2005). Esto es resultado de una combinación de factores que se retroalimentan. Los restos, si existen, suelen ser escasos, por lo que muchas veces no se emplean estrategias adecuadas de recuperación. Se recuperan pocos y por casualidad. Ello no impide que los restos carpológicos puedan ser muy útiles para la reconstrucción de la paleovegetación y de las actividades humanas.

Un total de 17 carporrestos (además de varios fragmentos de reducidas dimensiones) procedentes del Nivel XI fueron seleccionados a simple vista. La observación con lupa binocular (Leica S8APO) de sus caracteres morfológicos y su comparación con especímenes actuales de la colección de referencia del Instituto Internacional de Investigaciones Prehistóricas de Cantabria y fotografías SEM (Matsutani 1987; Messager et al. 2008; Simchoni y Kislev 2011) ha permitido 
establecer su pertenencia a la misma especie. La comparación con ejemplares actuales es viable gracias a que no ha habido cambios drásticos en la flora desde el Plioceno. La evolución de los ecosistemas ha consistido básicamente en respuestas migratorias a los ciclos glacial-interglacial.

Algunos de los carporrestos son ejemplares completos, otros son mitades regulares y fragmentos irregulares de endocarpo de fruto. Se conservan mineralizados-carbonizados. Su identificación es clara a nivel de género Celtis spp: son endocarpos de tendencia globular, de unos $5 \mathrm{~mm}$ de diámetro, con paredes gruesas $( \pm 750 \mu \mathrm{m})$ (Fig. 8). Sin embargo, en la bibliografía faltan criterios específicos consistentes de identificación. Además esta puede complicarse por hibridaciones (Simchoni y Kislev 2011): algunos autores consideran el tamaño como criterio diagnóstico (Messager et al. 2008) y otros el reticulado (Matsutani 1987; Zarafshar et al. 2010; Simchoni y Kislev 2011). El fuerte reticulado de la parte exterior del endocarpo, con un patrón muy marcado de 4 líneas rectas equidistantes de ápice a base y otro polígonal isodiamétrico poco denso y un poco menos prominente, indica que se trata de Celtis tipo australis. En cambio, según el tamaño, que suele ser un criterio discutible para la identificación de ejemplares fósiles, es ligeramente in- ferior a cualquiera de los propuestos como diagnósticos.

En la actualidad, solo hay una especie del género Celtis en la Península Ibérica (Navarro y Castroviejo 2005), el almez (C. australis L.), que aparece de forma dispersa en la zona de estudio (López Vélez 1996). Sin embargo, no es descartable que en el Pleistoceno existieran especies localizadas hoy en otros lugares de Europa (Simchoni y Kislev 2011): C. tournefortii Lam., $C$. caucasica Willd. y C. glabrata Steven ex Planch. C. australis es un taxón circunmediterráneo que excepcionalmente puede penetrar en formaciones interiores más húmedas. Las otras tres especies son más continentales (Simchoni y Kislev 2011) y particularmente $C$. tournefortii Lam. es buen resistente a la sequía (Messager et al. 2008). En cualquier caso, el género Celtis spp. incluye árboles pequeños o arbustos, de la familia de las ulmáceas, que crecen aislados o en pequeños grupos, sin formar bosques. Son caducifolios, crecen en bosques o ambientes rupícolas (barrancos, grietas de rocas, etc.), sobre suelos frescos, sueltos y pedregosos, indiferentes al substrato, entre 200-1200 m. (Navarro y Castroviejo 2005).

Las drupas (el exterior carnoso del hueso o endocarpo) de Celtis ssp. son comestibles, aunque el hueso ocupa gran parte del fruto. Las de C. glabrata se preparan en pasteles y gachas (Simchoni y Kislev 2011). Las drupas de C. aus-
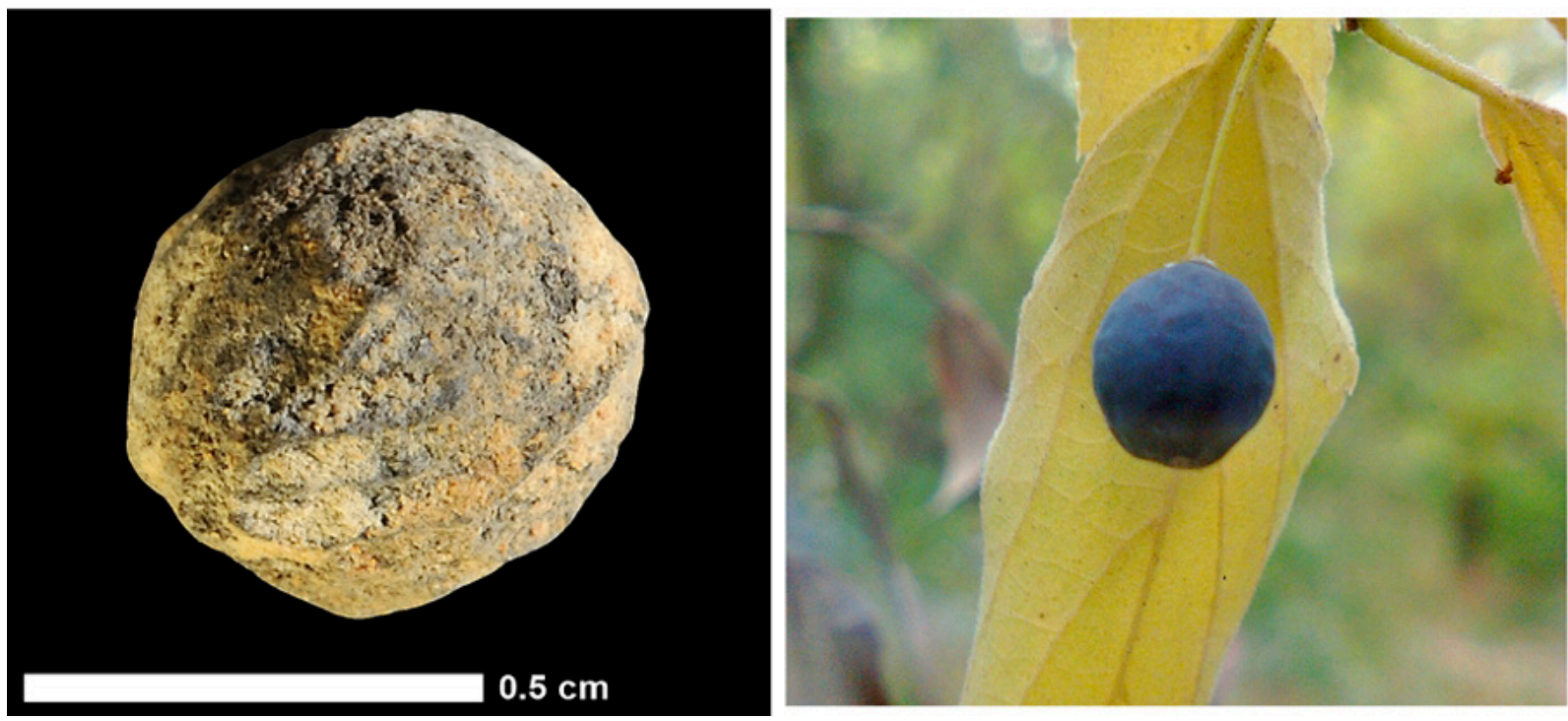

Fig. 8. Carporresto de Celtis tp. australis, procedente del nivel XI de la Cueva del Niño (izquierda). Foto I. LópezDóriga. Imagen del fruto en vivo (derecha). Foto D. Nàydenov, Wikipedia. 
tralis son dulces y comestibles en crudo o en forma de licor (Renfrew 1973; Tardío et al. 2006). Las semillas (situadas en el interior del hueso o endocarpo) también son comestibles en crudo o cocinadas y se las puede extraer el aceite con fines culinarios (Fern 1992-2010). Las hojas de C. australis también son comestibles (Hanelt 2001). Las hojas secas y el fruto a medio madurar, o una decocción de ambos, tienen propiedades medicinales (Fern 1992-2010; Hanelt 2001). Además, de la corteza se obtiene un tinte amarillo (Fern 1992-2010). La madera es apreciada para usos múltiples por su elasticidad y duración (Navarro y Castroviejo 2005; Simchoni y Kislev 2011). En la Sierra del Segura, está documentado su consumo esporádico en la alimentación tradicional (Verde López et al. 2003; Rivera Núñez et al. 2004).

Los endocarpos de este género son muy resistentes dado que, por su composición, se mineralizan con facilidad. Por ello, han sido recuperadas en numerosos yacimientos euroasiáticos desde el Pleistoceno Inferior hasta el Holoceno (Matsutani 1987; Messager et al. 2008; Simchoni y Kislev 2011). Algunos autores consideran que, en hallazgos pocos numerosos, los endocarpos pudieron ser aportados por aves migratorias, método de reproducción para el que está adaptado el género (Simchoni y Kislev 2011). Los roedores también pudieron aportarlos como provisiones de semillas; sin embargo, en los endocarpos estudiados, no hay huellas de roído evidentes a bajos aumentos.

Parece razonable suponer que, en la Cueva del Niño, el aporte es antrópico y evidencia un aprovechamiento de los recursos alimenticios locales. Es poco probable que una planta con tantos usos posibles para cada una de sus partes pasara por completo desapercibida para los grupos neandertales y que su relativa abundancia en el yacimiento fuera totalmente accidental.

\section{CRONOLOGÍA DE LOS NIVELES DE PALEOLÍTICO MEDIO}

En un primer momento, se atribuyó a una filiación musteriense (véase más abajo) la secuencia comprendida entre los Niveles VI a XI a partir de los ratios de sedimentación de varios yacimientos, así como de criterios tipológicos y tecnológicos de la industria lítica. No obstante, para concretar la cronología de la secuencia se seleccionaron muestras de varios niveles para su datación radiocarbónica (AMS sin ultrafiltración y AMS mediante ultrafiltración) y mediante racemización de aminoácidos $(A A R)$.

Para la datación radiocarbónica por ultrafiltración, un tratamiento previo destinado a eliminar posibles contaminaciones de la muestra, se seleccionaron 22 huesos, procedentes de los Niveles VII a XI de la Trench 2. Ninguna de ellas pudo fecharse: la escasa cantidad de nitrógeno que contenía el hueso implicaba la ausencia de colágeno requerido para la datación (Brock et al. 2012).

Las muestras seleccionadas para su datación por 14C AMS en el Centre for Applied Isotope Studies (CAIS) de la Universidad de Georgia (EE.UU.), también de la Trench 2, fueron un fragmento de hueso (unos 3 gr de peso) del Nivel IV y varios (18 gr en total) del III. Al resultar demasiado pobres en colágeno para su datación a partir de molécula proteica se trataron con ácido diluido para eliminar el carbonato secundario y obtener bio-apatito purificado (Cherkinsky y Chataigner 2010). Este tratamiento permitió obtener dataciones de ambas muestras a pesar de su alto grado de degradación.

Teniendo en cuenta la filiación musteriense de las industrias asociadas a estos niveles, el rango cronológico de las fechas obtenidas resultó sorprendentemente reciente (entre 33.470 y 31.975 calBP, Tab. 4). Estas fechas podrían llegar a encajar entre las manejadas en otros conjuntos mus-

\begin{tabular}{|c|c|c|c|c|}
\hline NIVEL & LAB. ID & 14C BP & Rango CalBP* & Material / Método \\
\hline IV & UGAMS-7737 & $28.270 \pm 80$ & $33.030-31.975$ & Hueso / AMS-Bio-apatito. \\
\hline III & UGAMS-7739 & $28.660 \pm 90$ & $33.470-32.695$ & Hueso / AMS-Bio-apatito. \\
\hline
\end{tabular}

Tab. 4. Dataciones por 14C AMS obtenidas para los Niveles III y IV de la Cueva del Niño (Aýna, Albacete).

* OxCal 4.1, Curva IntCal 09, 2。 
terienses tardíos identificados en la Península Ibérica (Zilhão 2006; Baena et al. 2012) pero su fiabilidad es baja debido al posible rejuvenecimiento de las muestras por la absorción de carbonatos (Cherkinsky y Chataigner 2010).

Se decidió emplear el método de racemización de aminoácidos $(A A R)$ ante la probabilidad de que fuera imposible datar los niveles más antiguos de la secuencia mediante 14C. El método se basa en la transformación de los L-aminoácidos a D-aminoácidos tras la muerte de todo ser orgánico (Hare et al. 1980). La datación fue realizada en el Laboratorio de Estratigrafía Biomolecular del Departamento de Ingeniería Geológica e Ingeniería Química y Combustibles de la ETSI de Minas de la Universidad Politécnica de Madrid.

Se seleccionaron 6 restos dentarios de Equus y 1 de Capra procedentes de los Niveles X y XI. De los niveles superiores de la secuencia se escogieron una pieza dentaria de Capra y otra de Equus (Nivel I) y dos piezas dentarias de Equus (Nivel II). Solo se obtuvieron datos coherentes en tres de los 11 restos analizados: uno del Nivel XI y las dos muestras del Nivel II. En el resto la abundancia de los diversos enantiómeros de los aminoácidos estaban por debajo del nivel de detección mínimo y, por lo tanto, los valores no eran fiables. La edad de las muestras se determinó introduciendo los valores $\mathrm{D} / \mathrm{L}$ del ácido aspártico en el algoritmo de cálculo de edad establecido para el colágeno de la dentina de osos fósiles de la Península Ibérica (Ursus deningeri y Ursus spelaeus) (Torres et al. 2002). La racemización es un proceso género-dependiente pero se ha comprobado que las diferencias de racemización en el colágeno de mamíferos son despreciables para los propósitos de datación.

La datación del Nivel XI arrojó una fecha 55.5 ka BP y las dos muestras del Nivel II resultaron en sendas estimaciones de 100.31 ka BP y 73.81 ka BP (Tab. 3). La fecha del Nivel XI parece perfectamente coherente con su posición estratigráfica y asignación cultural. En cambio, las dataciones del Nivel II sorprenden al tratarse del estrato superior de la secuencia, asignado al Neolítico Antiguo por la aparición de cerámicas de tipo cardial (Martí Oliver 1988). Esto podría indicar un problema en la datación por AAR o tener una explicación tafonómica.

La explicación de este aparente desfase cronológico podría estar en el aporte a los estratos superiores de la secuencia de materiales antiguos, procedentes de una actuación furtiva realizada justo a la entrada de la cavidad antes de la excavación de 1973. En imágenes de prensa del año 1970 (diario ABC, domingo 11 de Octubre) ya aparece este profundo sondeo. En este sentido, debe tenerse en cuenta que el Nivel II es prácticamente superficial y en él aparecen materiales propios del Paleolítico Medio, como lascas Levallois, bifaces o núcleos de tipo Levallois y Quina, mezclados con otros claramente post-paleolíticos, como microlitos geométricos. Podría tratarse por lo tanto de un nivel post-pleistoceno, en el que se habrían colado materiales más antiguos, aunque no se documentó ninguna alteración del depósito durante el proceso de excavación. De momento resulta imposible esclarecer esta problemática.

La datación de los diversos niveles de ocupación antrópica de la secuencia estratigráfica de la Cueva del Niño resultó problemática, impidiendo una valoración exhaustiva y precisa de la evolución de la ocupación paleolítica de la cavidad. A modo de hipótesis, cabe una aproximación genérica a la cronología de las ocupaciones del Paleolítico Medio, sin olvidar ni las evidencias de adscribirles a otros períodos paleolíticos y postpaleolíticos (que no serán tratadas en este artículo), ni tampoco el reducido número de dataciones disponibles por el momento y las limitaciones de los métodos de datación empleados.

La obtención de fechas en torno al 29 ka BP para los Niveles IV y III por bio-apatito podría ser interpretada como la pervivencia en la región de un Paleolítico Medio tardío y, por lo tanto, de las poblaciones neandertales supuestamente asociadas a dichas industrias. Ello estaría en línea con lo propuesto para otros lugares del sur de la Península Ibérica, como el cercano sitio de El Palomar (6), Zafarraya (Hublin et al. 1995; Michel et al. 2003), Gorham's Cave (Finlayson et al. 2006), Carihuela (Vega Toscano et al. 1988; Fernández et al. 2007), Cueva Negra o Caldeirão (Zilhão 2006), entre otros (Baena et al. 2012). Sin embargo, al igual que ha sido apuntado en esos casos (Zilhão y Pettitt 2006; Maroto et al. 2012; Wood et al. 2013), las fechas obtenidas en la Cueva del Niño son problemáticas,

(6) Peña Alonso, P. D. L. Sobre la unidad tecnológica del Gravetiense en la Península Ibérica: implicaciones para el conocimiento del Paleolítico Superior Inicial. Tesis Doctoral inédita. Departamento de Prehistoria. Universidad Complutense de Madrid. Madrid, 2011. 
pudiendo haber sufrido un proceso de rejuvenecimiento (Cherkinsky y Chataigner 2010).

La datación por AAR ha sido también problemática. El resultado de la del Nivel XI en torno al 55 ka BP sería consistente con su posición estratigráfica, pero la correspondiente al Nivel II, el superior de la secuencia, lo sitúa en contextos de Paleolítico Medio Antiguo.

Llama la atención la evidente discontinuidad entre los Niveles III-IV y el suprayacente Nivel II, cuya cronología, descontando los elementos intrusivos más antiguos, probablemente remita al Neolítico. Este hiato en la secuencia podría deberse a un episodio erosivo, quiza por reactivación kárstica, que habría afectado a los estratos correspondientes al Pleistoceno Superior. A la espera de nuevas excavaciones que permitan verificar esta hipótesis carecemos de elementos que aclaren esta discontinuidad.

\section{DISCUSIÓN Y CONCLUSIONES}

La Península Ibérica es un escenario fundamental para estudiar la evolución y posterior desaparición de las sociedades neandertales. Una de las principales cuestiones a tener en cuenta al abordar esta problemática es la enorme diversidad de comportamientos que se deducen del análisis del registro arqueológico, derivada tanto de la evolución histórica de las sociedades neandertales como de la propia variabilidad biogeográfica de la Península Ibérica (Vaquero et al. 2006).

En este sentido, la Cueva del Niño ofrece elementos para aproximarnos a las distintas formas de organización económica y social de las poblaciones neandertales a lo largo del tiempo, es decir, cómo dichas sociedades las ejecutaron en un área geográfica concreta. El limitado registro arqueológico del yacimiento obliga a ser cautelosos en su interpretación, pero pueden apuntarse cambios entre el conjunto de niveles inferiores de la secuencia, fundamentalmente el Nivel XI, y las últimas ocupaciones musterienses de la cavidad, localizadas en el paquete formado por los Niveles III-IV. En ambos casos los ocupantes de la Cueva del Niño aparecen integrados en redes de movilidad amplias que podrían incluir el acceso tanto a la Meseta Sur como a la costa mediterránea (Davidson 1986; Serna López 1997) y la explotación de los recursos locales que ofrece el variado ecosistema circundante. Sin embargo di- fieren notablemente las estrategias de subsistencia y de aprovisionamiento de instrumental lítico desarrolladas en cada momento. Esto puede observarse incluso a pesar de lo reducido del registro disponible, puesto que la evidencia procedente de los dos paquetes estratigráficos es claramente diferente.

En los niveles inferiores la estrategia se orienta a favorecer la disponibilidad de utillaje fabricado en materias primas de calidad como el sílex. Para ello se importan raederas, algunas de ellas de tipo Quina, que son reavivadas poniendo en práctica al mismo tiempo una estrategia ramificada que permite disponer de una segunda generación de útiles. Se constata asimismo una mayor variabilidad en la fauna, que incluye las especies más locales, como la cabra o el ciervo, y restos de ungulados de gran talla como el caballo, el uro y puede que el rinoceronte. Ello indicaría la explotación de territorios alejados del yacimiento, como las penillanuras existentes sobre el cañón del río Mundo, o la cuenca baja del mismo y el Campo de Hellín. Ambas evidencias parecen mostrar una gestión basada en una alta movilidad y en la explotación integrada de distintos tipos de biotopos y recursos.

En los niveles superiores, por el contrario, las estrategias de aprovisionamiento tecnológico descansan casi exclusivamente en las materias primas locales, a las que se añaden probablemente un número reducido de útiles importados, sin que se observe ahora un afán específico en la conservación del utillaje. Algo semejante puede deducirse del espectro faunístico, donde prácticamente solo hay ungulados de talla media, ciervos y cabras, abundantes en el entorno. Estas evidencias ponen de relieve también una alta movilidad, pero al mismo tiempo evidencian una mayor dependencia del entorno.

En definitiva, las ocupaciones del yacimiento a lo largo del Paleolítico Medio parecen caracterizarse fundamentalmente por su carácter esporádico y baja intensidad. Esta imagen podría derivarse en parte del escaso registro arqueológico pero se observan cambios en las estrategias de explotación del medio. Así en la parte alta de la secuencia los recursos estrictamente locales, tanto minerales como cinegéticos, tienen una importancia capital, mientras que en los momentos más antiguos hay un aporte más sistemático de recursos exógenos. Pensamos por ello que las ocupaciones de los Niveles X y XI de la Cueva del 
Niño formarían parte probablemente de un esquema de ocupación y explotación del territorio planificado y jerarquizado, que integraría diversos asentamientos a lo largo de la cuenca del río Mundo (Serna López 1997). En cambio, las del Nivel III-IV serían más simples y dependientes de los recursos locales y estarían destinadas a satisfacer las necesidades más inmediatas.

La tendencia observada en la Cueva del Niño parece documentarse en otros conjuntos del $\mathrm{Pa}$ leolítico Medio de la Submeseta Sur como Jarama VI (Lorenzo et al. 2012; contra Kehl et al. 2013), de la zona de Levante como Sima de Las Palomas (Walker et al. 2008), Quebrada (Villaverde Bonilla et al. 2008), El Salt (Galván Santos et al. 2001) o Aviones (Zilhão et al. 2010a), o del Sur de la península como el nivel IV de Gorham's Cave (Pacheco et al. 2012), el nivel 14 de Bajondillo (Cortés Sánchez 2007b) o Carigüela (Vega Toscano et al. 1988). En el Norte de la península evidencian una tendencia semejante el nivel Lmc de Arrillor (Bermúdez de Castro y Sáenz de Buruaga 1997), el nivel SC1 de Cova Gran (Martínez Moreno et al. 2010), las ocupaciones de Fuentes del San Cristobal (Maroto et al. 2012) o los niveles más recientes de Esquilleu (Baena et al. 2012). Quizá haya que unirles el nivel $\mathrm{E}$ de Peña Miel (Utrilla Miranda et al. 1987) o los niveles superiores de Moros de Gabasa (Santamaría Álvarez et al. 2008), entre otros.

En el contexto general de la Península Ibérica estos cambios en los patrones de asentamiento, la gestión de recursos y las estrategias de subsistencia han sido interpretadas como una crisis entre las poblaciones neandertales de finales del Paleolítico Medio, que muestran una menor movilidad, un uso más intensivo de las materias primas líticas locales y la ocupación preferencial de áreas marginales. Dichas transformaciones parecen indicar una ruptura de las redes de movilidad que puede ser causa o efecto de una fragmentación poblacional que, intuimos, pudo afectar de manera inexorable a las posibilidades de supervivencia de las poblaciones neandertales en la Península Ibérica (Banks 2008 contra Jennings et al. 2011).

La cronología de este proceso se está discutiendo en la actualidad no solo por los problemas existentes de definición estratigráfica y cultural (Zilhão 2006) sino por los avances en el tratamiento de las muestras de radiocarbono que están llevando a reconsiderar buena parte de las dataciones más recientes del final del Paleolítico Me- dio (Maroto et al. 2012; Wood et al. 2013, Highman et al. 2014). Estas reservas no impiden constatar un desfase entre las fechas Auriñacienses más antiguas del Norte de la Península Ibérica (37-36 kyr BP) y las del Sur (33-30 kyr BP) (Zilhão et al. 2010b; Maroto et al. 2012). En este intervalo podríamos situar cómodamente algunas de las fechas más recientes obtenidas en niveles musterienses de Cueva Antón, Sima de las Palomas o Gorham's Cave (Zilhão et al. 2010a).

Los problemas encontrados en la datación de la secuencia de la Cueva de El Niño también impiden valorar el contexto cronológico de las ocupaciones musterienses y los cambios apuntados en las estrategias de subsistencia que se enmarcan al final del Paleolítico Medio y/o durante la sustitución de unas poblaciones humanas por otras. A pesar de estas limitaciones, la secuencia aporta nueva evidencia sobre la variabilidad de los procesos de cambio producidos en el seno de las sociedades neandertales. Nos referimos a la aparente disgregación y aislamiento de los grupos neandertales y a su propuesta mayor continuidad en el sur de la Península Ibérica al final del Paleolítico Medio. Además la localización de la Cueva del Niño en el contacto entre el Levante, la Meseta Sur y la región andaluza permite incorporar sus datos a la caracterización particular de los ritmos de las dinámicas de cambio de las sociedades neandertales de la mitad meridional de la península.

En definitiva, y asumiendo las limitaciones de los métodos de datación empleados, el yacimiento de la Cueva del Niño constituye una nueva fuente de información sobre el Paleolítico Medio, un crucial período de la Prehistoria de la Península Ibérica, que habrá de ser ampliada en futuros trabajos.

\section{AGRADECIMIENTOS}

El programa de "Ayudas a la Investigación" del Instituto de Estudios Albacetenses "Don Juan Manuel" en 2010 hizo posible la revisión, estudio y datación de los materiales arqueológicos procedentes de las excavaciones de 1973 en la Cueva del Niño. Iain Davidson colaboró de modo fundamental en la revisión del yacimiento, al informar sobre los trabajos de excavación en el mismo. El Museo de Albacete, y en especial Blanca Gamo, prestaron su ayuda y disponibilidad para 
la consulta del material allí depositado. Jesús Moreno del Museo Etnográfico-Oficina de Turismo de Aýna ayudó también en la investigación. ABMA hizo el estudio arqueozoológico durante el disfrute de una Beca Postdoctoral concedida por el Gobierno Vasco en la Universidad de Cambridge. Actualmente es Investigadora Ramón y Cajal (RYC-2011-00695) en la Universidad de Cantabria. Jessica Ripengal nos ayudó en el Grahame Clark Laboratory del McDonald Institute for Archaeological Research (Cambridge). AGM realizó este trabajo durante su contrato postdoctoral en la Universidad de Cantabria en el IIIPC. ILD es becaria predoctoral de dicha Universidad. Agradecemos a Rachel Wood (Nacional University of Australia) su interés por datar los niveles musterienses del yacimiento y a los revisores anónimos sus comentarios y aportaciones.

\section{BIBLIOGRAFÍA}

Almagro Gorbea, M. 1971: “La cueva del Niño (Albacete). La cueva de la Griega (Segovia). Dos yacimientos de arte rupestre recientemente descubiertos en la Península Ibérica". Trabajos de Prehistoria 28: 9-62.

Almagro Gorbea, M. 1972: "Descubrimiento de una cueva con arte rupestre paleolítico en la provincia de Albacete". Simposio Internacional de Arte Rupestre de Santander (Santander-Oviedo 1970): 475-497. Santander.

Aura Tortosa, J. E.; Carrión Marco, Y.; Estrelles, E. y Jordà, G. P. 2005: "Plant economy of huntergatherer groups at the end of the last Ice Age: plant macroremains from the cave of Santa Maira (Alacant, Spain) ca. 12000-9000 BP". Vegetation History and Archaeobotany 14: 542-550.

Badal García, E. 1998: "El interés económico del pino piñonero para los habitantes de la Cueva de Nerja”. En J. L. Sanchidrián y M. D. Simón (eds.): Las culturas del Pleistoceno Superior en Andalucía. Homenaje al profesor Francisco Jordá Cerdá. Patronato de la Cueva de Nerja. Malaga: 287-300.

Baena, J.; Carrión, E.; Cuartero, F. y Fluck, H. 2012: "A chronicle of crisis: The Late Mousterian in north Iberia (Cueva del Esquilleu, Cantabria, Spain)". Quaternary International 247: 199-211.

Banks, W. E.; D’Errico, F.; Peterson, A. T.; Kageyama, M.; Sima, A. y Sánchez Goñi, M. F. 2008: "Neanderthal Extinction by Competitive Exclusion". PLoS ONE 3 (12): e3972.

Bermúdez de Castro, J. M. y Sáenz de Buruaga, A. 1997: "Étude Préliminare du site Pléistocène Su- périeur à hominidé d'Arrillor (Pays Basque, Espagne)". L'Anthropologie 103: 633-639.

Bourguignon, L. 1996: "La conception de debitage Quina”. Quaternaria Noua VI: 149-166.

Bourguignon, L.; Faivre, J. P. y Turq, A. 2004: "Ramification des chaînes opératoires: une spécificité du Moustérien?'. Paleo 16: 37-48.

Brock, F.; Wood, R.; Higham, T.; Ditchfield, P.; Bayliss, A. y Ramsey, C. B. 2012: "Reliability of Nitrogen Content $(\% \mathrm{~N})$ and Carbon:Nitrogen Atomic Ratios $(\mathrm{C}: \mathrm{N})$ as Indicators of Collagen Preservation Suitable for Radiocarbon Dating". Radiocarbon 54 (3-4): 879-886.

Carrión Santafé, E.; Baena Preysler, J.; Conde Ruiz, C.; Cuartero Monteagudo, F. y Roca, M. 2008: "Variabilidad tecnológica en el musteriense de Cantabria". Treballs d'Arqueologia 14: 279-318.

Cherkinsky, A. y Chataigner, C. 2010: "14C Ages of bone fractions from Armenian prehistoric sites". Radiocarbon 52, 2-3: 569-577.

Cortés Sánchez, M. 2007a: "El Paleolítico Medio y Superior en el sector central de Andalucía (Córdoba y Málaga)". Museo de Altamira. Monografias 22. Ministerio de Cultura, Madrid.

Cortés Sánchez, M. 2007b: Cueva de Bajondillo (Torremolinos). Secuencia cronocultural y paleoambiental del Cuaternario reciente en la Bahía de Málaga. Centro de Ediciones de la Diputación Provincial de Málaga. Málaga.

Cortés Sánchez, M. 2011: "El Paleolítico medio meridional ibérico. Reflexiones en torno a su entidad y definición". En J. J. Fernández Caro y R. Baena Escudero (eds.): Arqueología, Paleontología y Geomorfología del Cuaternario en España: X Aniversario del Seminario Francisco Sousa (La Rinconada, Sevilla): 259-270. Sevilla.

Costamagno, S.; Liliane, M.; Cédric, B.; Bernard, V. y Maureille, B. 2006: "Les Pradelles (Marillacle-Franc, France): a mousterian reindeer hunting camp?". Journal of Anthropological Archaeology 25: 466-484.

Crowe, W. 1985: "Técnicas de recuperación integral de los datos obtenidos en los sedimentos de yacimientos Prehistóricos". En I. Barandiarán (ed.): Excavaciones en la cueva del Juyo. Subdirección General de Arqueología y Etnografía. Madrid.

Davidson, I. 1986: "The geographical study of of Late Paleolithic stages in Eastern Spain". En G. N. Bailey y P. Callow (eds.): Stone Age Prehistory. Cambridge University Press. Cambridge: 95-118.

Davidson, I y García Moreno, A. 2013: "La excavación arqueológica de la Cueva el Niño (Ayna, Albacete) de 1973: secuencia estratigráfica y materiales". Al-Basit 58: 91-117.

Fern, K. 1992-2010: "Plants For A Future: Plant Species Database, http://www.pfaf.org" (acceso 23VII-2014). 
Fernández Peris, J.; Barciela, V.; Blasco, R.; Cuartero, F. y Sañudo, P. 2008: "El Paleolítico Medio en el territorio valenciano y la variabilidad tecno-económica de la Cova del Bolomor". Treballs d'Arqueologia 14: 141-169.

Fernández Peris, J.; Guillem Calatayud, P. M. y Martínez Valle, A. 1997: Cova del Bolomor: los primeros habitantes de las tierras valencianas. Diputación de Valencia, Valencia.

Fernández, S.; Fuentes, N.; Carrión, J. S.; González Sampériz, P.; Montoya, E.; Gil, G.; Vega Toscano, G. y Riquelme, J. A. 2007: "The Holocene and Upper Pleistocene pollen sequence of Carihuela Cave, southern Spain". Geobios 40: 75-90.

Finlayson, C.; Fa, D. A.; Jiménez Espejo, F.; Carrión, J. S.; Finlayson, G.; Giles Pacheco, F.; Rodríguez Vidal, J.; Stringer, C. y Martínez Ruiz, F. 2008: "Gorham's Cave, Gibraltar--The persistence of a Neanderthal population". Quaternary International 181: 64-71.

Finlayson, C.; Giles Pacheco, F.; Rodríguez-Vidal, J.; Fa, D. A.; Gutiérrez López, J. M.; Santiago Pérez, A.; Finlayson, G.; Allue, E.; Baena Preysler, J.; Caceres, I.; Carrión, J. S.; Fernández Calvo, Y.; Gleed-Owen, C. P.; Jiménez Espejo, F. J.; López, P.; López Sáez, J. A.; Riquelme Cantal, J. A.; Sánchez Marco, A.; Giles Guzman, F.; Brown, K.; Fuentes, N.; Valarino, C. A.; Villalpando, A.; Stringer, C. B.; Martínez Ruiz, F. y Sakamoto, T. 2006: "Late survival of Neanderthals at the southernmost extreme of Europe". Nature 443: 850-853.

Gale, R. y Carruthers, W. 2000: "Charcoal and Charred Seed Remains from Middle Palaeolithic Levels at Gorham's and Vanguard Caves". En C. B. Stringer et al. (eds.): Neanderthals on the edge: 150th anniversary conference of the Forbes' Quarry discovery, Gibraltar. Oxbow Books. Oxford: 207-210.

Galván Santos, B.; Hernández Gómez, C. M.; Alberto Barroso, V.; Barro Rois, A.; Francisco Ortega, I. y Rodríguez Rodríguez, A. 2001: "Neandertales en los Valles de Alcoi (Alicante, España). El Salt como un Centro de Intervención Referencial". Tabona 10: 7-33.

Garate Maidagan, D. y García Moreno, A. 2011: "Revisión crítica y contextualización espacio-temporal del arte parietal paleolítico de la cueva de El Niño (Ayna, Albacete)". Zephyrus LXVIII: 15-39.

García Atiénzar, G. 2011: "El contexto arqueológico del Arte Rupestre Levantino en el Campo de Hellín (Albacete)". Zephyrus LXVIII: 63-86.

Hanelt, P. 2001: Mansfeld's encyclopedia of agricultural and horticultural crops. http://mansfeld.ipkgatersleben.de/

Hare, P. E.; Hoering, T. C. y King, K. J. 1980: Biogeochemistry of Amino Acids. Wiley. New York.

Highman, T.; Douka, K.; Wood, R.; Bronk Ramsey, Ch.; Brock, F.; Basell, L.; Camps, M.; Arrizabalaga,
A.; Baena, J.; Barroso-Ruíz, C.; Bergman, Boitard, C.; Boscato, P.; Caparrós, M.; Conard, N. J.; Draily, Ch.; Froment, A.; Galván, B.; Gambassini, P.; García-Moreno, A.; Grimaldi, S.; Haesaerts, P.; Holt, B.; Iriarte-Chiapusso, M. J.; Jelinek, A.; Jordá Pardo, J. F.; Maíllo-Fernández, J. M.; Marom, A.; Maroto, J.; Menéndez, M.; Metz, L.; Morin, E.; Moroni, A.; Negrino, F.; Panagopoulou, E.; Peresani, M.; Pirson, S.; Rasilla, M. de la; Riel-Salvatore, J.; Ronchitelli, A.; Santamaría, D.; Semal, P.; Slimak, L.; Soler, J.; Soler, N.; Villaluenga, A.; Pinhasi, R. y Jacobi, R. 2014: "The timing and spatiotemporal patterning of Neanderthal disappearance". Nature 512: 306-309.

Higgs, E.; Davidson, I. y Bernaldo de Quirós, F. 1976: "Excavaciones en la Cueva de El Niño, Ayna (Albacete)". Trabajos de Prehistoria 5: 91-96.

Hublin, J. J.; Barroso Ruiz, C.; Medina Lara, P.; Fontugne, M. y Reyss, J. L. 1995: "The Mousterian site of Zafarraya (Andalucia, Span): dating and implications on the Paleolithic peopling process of Western Europe". Comptes-Rendus de l'Académie des Sciences de Paris Série IIa 321: 931-937.

Jennings, R. P.; Finlayson, C.; Fa, D. A. y Finlayson, G. 2011: "Southern Iberia as a refuge for the last Neanderthal populations". Journal of Biogeography 38, 10: 1873-1885 doi:10.1111/j.13652699.2011.02536.x: 1-13.

Jiménez Lorente, S.; Jordán Montes, J. y Ayala Juan, M. M. 1995-1996: "El taller de la ermita del Pedernaloso (Hellín, Albacete). Nuevas aportaciones al estudio de los talleres de sílex al aire libre". AnMurcia 11-12: 17-22.

Khel, M.; Burrow, C.; Hilgers, A., Navazo, M.; Pastoors, A.; Weniger, G.C.; Wood, R. y Jordá Pardo, J. 2013: "Late Neanderthals at Jarama VI (central Iberia)?". Quaternary Research 80 (2): 218-234.

López Campuzano, M. y Jordán Montés, J. F. 1995: "El yacimiento musteriense de la laguna de 'El Polope' (Tobarra, Albacete)". Al-Basit 37: 5-35.

López Vélez, G. 1996: Flora y vegetación del Macizo del Calar del Mundo y Sierras adyacentes del sur de Albacete. Instituto de Estudios Albacetenses 'Don Juan Manuel'. Albacete.

Lorenzo, C.; Navazo, M.; Díez, J. C.; Sesé, C.; Arceredillo, D. y Jordá Pardo, J. F. 2012: "New human fossil to the last Neanderthals in central Spain (Jarama VI, Valdesotos, Guadalajara, Spain)". Journal of Human Evolution 62: 720-725.

Marín Arroyo, A. B. 2010: Arqueozoología en el Cantábrico Oriental durante la transición Pleistoceno/ Holoceno: La Cueva del Mirón. Universidad de Cantabria. Santander.

Marín Arroyo, A. B. y González Morales, M. R. 2009: "Comportamiento económico de los últimos cazadores-recolectores y primeras evidencias de domesticación en el occidente de Asturias. La 
cueva de Mazaculos II". Trabajos de Prehistoria 66, 1: 47-74.

Maroto, J.; Vaquero, M.; Arrizabalaga, Á.; Baena, J.; Baquedano, E.; Jordá Pardo, J. F.; Juliá, R.; Montes Barquín, R.; Van Der Plicht, J.; Rasines, P. y Wood, R. 2012: "Current issues in late Middle Palaeolithic chronology: New assessments from Northern Iberia". Quaternary International 247: 15-25.

Martí Oliver, B. 1988: "Vaso neolítico procedente de la Cueva del Niño (Ayna, Albacete)". Homenaje a Samuel de los Santos. Instituto de Estudios Albacetenses 'Don Juan Manuel'. Albacete: 77-80

Martínez Moreno, J.; Mora, R. y De La, Torre, I.. 2010: "The Middle-to-Upper Palaeolithic transition in Cova Gran (Catalunya, Spain) and the extinction of Neanderthals in the Iberian Peninsula". Journal of Human Evolution 58: 211-226.

Matsutani, A. 1987: "Plant remains from the 1984 excavations at Douara Cave". En T. Akazawa y Y. Sakaguchi (eds.): Paleolithic Site of Douara Cave and Paleogeography of Palmyra Basin in Syria. Part IV: 1984 Excavations. Tokyo University. Tokyo: 117-122.

Messager, E.; Lordkipanidze, D.; Ferring, C. R. y Deniaux, B. 2008: "Fossil fruit identification by SEM investigations, a tool for palaeoenvironmental reconstruction of Dmanisi site, Georgia". Journal of Archaeology Science 35: 2715-2725.

Michel, V.; Bard, E.; Dekanghe, D.; El Mansouri, M.; Falgéres, C.; Pettitt, P. B.; Yokohama, Y.; Barroso Ruiz, C. y Mallol Duque, C. 2003: "Geocronología del relleno de la cueva del Boquete de Zafarraya". En C. Barroso Ruiz (ed.): El Pleistoceno Superior de la cueva del Boquete de Zafarraya. Junta de Andalucía. Sevilla: 113-134.

Navarro, C. y Castroviejo, S. 2005: Flora Iberica: plantas vasculares de la Península Ibérica e Islas Baleares, 3 Ulmaceae. Real Jardín Botánico, CSIC. Madrid.

Navazo, M. y Díez, C. 2008: "Prado Vargas y la variabilidad tecnológica al finales del Paleolítico Medio en la Meseta norte". Treballs d'Arqueologia 14: 121-139.

Pacheco, F. G.; Giles Guzmán, F. J.; Gutiérrez López, J. M.; Pérez, A. S.; Finlayson, C.; Rodríguez Vidal, J.; Finlayson, G. y Fa, D. A. 2012: "The tools of the last Neanderthals: Morphotechnical characterisation of the lithic industry at level IV of Gorham's Cave, Gibraltar". Quaternary International 247: 151-161.

Renfrew, J. M. 1973: Paleoethnobotany. The prehistoric food plants of the Near East and Europe. Columbia University Press. New York.

Rios Garaizar, J. 2005: "Características de la producción lítica al final del Paleolítico Medio en el País Vasco. El caso del nivel B de Axlor (Dima, Bizkaia)”. En R. Montes Barquín y J. A. Lasheras
Corruchaga (eds.): Actas De La Reunión Científica: Neandertales Cantábricos. Estado de la Cuestión. Ministerio de Cultura. Madrid: 333-348.

Rios Garaizar, J. 2007: "Industria lítica y sociedad en la Transición del Paleolítico Medio al Superior del Cantábrico Oriental: la necesidad de un enfoque integral". Nivel Cero 11: 29-46.

Rios Garaizar, J. 2008: "Variabilidad tecnológica en el Paleolítico Medio de los Pirineos Occidentales: una expresión de las dinámicas históricas de las sociedades neandertales". Treballs d'Arqueologia 14: 171-194.

Rios Garaizar, J. 2010: “Organización económica de las sociedades neandertales: el caso del Nivel VII de Amalda (Zestoa, Gipuzkoa)". Zephyrus LXV: 15-37.

Rios Garaizar, J. 2012: Industria lítica y sociedad del Paleolítico medio al superior en torno al Golfo de Bizkaia. PubliCan, Ediciones de la Universidad de Cantabria. Santander.

Rivera Núñez, D.; Fajardo Rodríguez, J.; Verde López, A.; Obón De Castro, C. y Inocencio Petrel, C. 2004: "Las plantas y las setas (silvestres y sinantrópicas) recolectadas en la alimentación tradicional de la provincia de Albacete". En A. Verde López y J. D. Mora Moreno (eds.): II Jornadas sobre el medio natural en Albacete (Albacete 2001): 149-162. Albacete.

Rodríguez González, D. 2008: Los primeros agricultores de Castilla-La Mancha. El neolítico de la Meseta sur. Cueva de Montesinos. Ciudad Real.

Santamaría Álvarez, D.; Montes Ramírez, L. y Utrilla Miranda, P. 2008: "Variabilidad técnica del Paleolítico Medio en el valle del Ebro: la Cueva de los Moros I de Gabasa (Peralta de Calasanz, Huesca)". Treballs d'Arqueologia 14: 319-339.

Serna López, J. L. 1990: "Hallazgos musterienses en la cuenca media del río Mundo (Albacete)". $\mathrm{Al}$ Basit 26: 5-26.

Serna López, J. L. 1997: “Consideraciones sobre economía y ocupación del territorio durante la prehistoria inicial. El caso de los yacimientos paleolíticos y epipaleolíticos de la cuenca del río Mundo". $A r-$ chivo de Prehistoria Levantina 22: 57-71.

Serna López, J. L. 1999: El Paleolítico medio en la provincia de Albacete. Instituto de Estudios Albacetenses 'Don Juan Manuel'. Albacete.

Simchoni, O. y Kislev, M. 2011: "Early finds of Celtis australis in the southern Levant". Vegetation History and Archaeobotany 20: 267-271.

Soffer, O. 2000: "The Last Neanderthal". En D. Lordkipanidze, O. Bar-yosef y M. Otte (eds.): Early humans at the gates of Europe: Proceedings of the firts international symposium (Dmanisi, Tbilisi Georgia 1998). ERAUL, Études et recherches Archéologiques de l'Université de Liège 92. Liége: 139-145. 
Soressi, M. 2004: "L'industrie lithique des niveaux moustériens de Chez-Pinaud à Jonzac (Charentes), fouilles 1998-99. Aspects taphonomiques, économiques et technologiques". Préhistoire $d u$ SudOuest, supplément 8: 79-95.

Tardío, J.; Pardo de Santayana, M. y Morales, R. 2006: "Ethnobotanical review of wild edible plants in Spain". Botanical Journal of the Linnean Society 152: $27-71$.

Torres, T. de; Ortiz, J. E.; Llamas, F. J.; Canoira, L.; Juliá, R. y García-Martínez, M. J. 2002: "Bear dentine aspartic acid racemization analysis: a proxy for the dating of Pleistocene cave infills". Archaeometry 44: 417-426.

Utrilla Miranda, P.; Vilchez, J.; Barandiaran Maestu, I.; Altuna, J.; Gil, E. y López, P. 1987: La cueva de Peña Miel: Nieva de Cameros, La Rioja. Dirección General de Bellas Artes y Archivos, Ministerio de Cultura, Madrid.

Vaquero, M.; Maroto, J.; Arrizabalaga, A.; Baena, J.; Carrión, E.; Jordá Pardo, J. F.; Martinón, M.; Menéndez, M.; Montes Barquín, R. y Rosell, J. 2006: "The Neandertal-Modern Human Meeting In Iberia: A Critical View on the Cultural, Geographical and Chronological Data". En N. J. Conard (ed.): When Neanderthals and Modern Humans Met. Kerns Verlag. Tübingen: 419-439.

Vega Toscano, G.; Hoyos Gómez, M.; Ruiz Bustos, A. y Laville, H. 1988: "La séquence de lagrotte de la Carihuela (Piñar, Grenade): chronostratigraphie et paléoécologie du Pléistocène Supérieur au Sud de la Péninsule Ibérique". En M. Otte (ed.): L'Homme de Néandertal Actes du colloque internacional de Liège (1986). En H. Laville (ed.): L'environement 2. ERAUL, Études et recherches Archéologiques de l'Université de Liège. Liège: 169-180.

Verde López, A.; Rivera Núñez, D.; Heinrich, M.; Fajardo Rodríguez, J.; Inocencio Petrel, C.; Llorach, R. y Obón de Castro, C. 2003: "Plantas alimenticias recolectadas tradicionalmente en la provincia de Albacete y zonas próximas, su uso tradicional en la medicina popular y su potencial como nutracéuticos". Sabuco 4: 35-72.

Villaverde Bonilla, V. 2001: De Neandertales a Cromañones. Départament de Prehistòria i Arqueologia, Universitat de València. Valencia.
Villaverde Bonilla, V.; Eixea, A. y Zilhão, J. 2008: "Aproximación a la industria lítica del Abrigo de la Quebrada (Chelva, Valencia)". Treballs d'Arqueologia 14: 213-228.

Walker, M. J.; Gibert, J.; López, M. V.; Lombardi, A. V.; Pérez-Pérez, A.; Zapata, J.; Ortega, J.; Higham, T. F. G.; Pike, A.; Schwenninger, J. L.; Zilhão, J. y Trinkaus, E. 2008: "Late Neandertals in Southeastern Iberia: Sima de las Palomas del Cabezo Gordo, Murcia, Spain”. Proceedings of the National Academy of Sciences 105: 20631-20636.

Wood, R. E.; Barroso Ruiz, C.; Caparrós, M.; Jordá Pardo, J. F.; Galván Santos, B. y Higham, T. F. G. 2013: "Radiocarbon dating casts doubt on the late chronology of the Middle to Upper Palaeolithic transition in southern Iberia". Proceedings of the National Academy of Sciences, www.pnas.org/cgi/ doi/10.1073/pnas.1207656110.

Zarafshar, M.; Akbarinia, M.; Sattarian, A. y Maesen, L. J. G. V. D. 2010: "Pollen Morphology of Iranian Celtis (Celtidaceae-Ulmaceae)". Botanica Serbica 34 (2): 145-149.

Zilhão, J. 2006: "Chronoestratigraphy of the Middleto-Upper Paleolithic transition in the Iberian Peninsula". Pyrenae 37, 1: 7-84.

Zilhão, J.; Angelucci, D. E.; Badal-García, E.; D’Errico, F.; Daniel, F.; Dayet, L.; Douka, K.; Higham, T. F. G.; Martínez-Sámchez, M. J.; Montes-Bernarded, R.; Murcia-Mascarós, S.; Pérez-Sirvent, C.; RoldanGarcía, C.; Vanhaeren, M.; Villaverde, V.; Wood, R. y Zapata, J. 2010a: "Symbolic use of marine shells and mineral pigments by Iberian Neandertals". Proceedings of the National Academy of Sciences 107 (3): 1023-1028 doi/10.1073/pnas.0914088107.

Zilhão, J.; Davis, S. J. M.; Duarte, C.; Soares, A. M. M.; Steier, P. y Wild, E. 2010b: "Pego do Diabo (Loures, Portugal): Dating the Emergence of Anatomical Modernity in Westernmost Eurasia". PLoS ONE 5: e8880.

Zilhão, J. y Pettitt, P. 2006: "On the new dates for Gorham's cave and the late survival of Iberian Neanderthals". Before Farming: the archaeology and anthropology of hunter-gatherers 2006/3 Article 1 .

Zilhão, J. y Villaverde, V. 2008: "The Middle Paleolithic of Murcia". Treballs d'Arqueologia 14: 229-248. 